\title{
SOBRE EL LLAMADO "COMPROMISO ONTOLÓGICO"
}

I) Bajo el epígrafe "Sobre lo que hay" pueden formularse varias preguntas: “¿Hay algo?”, “¿Qué hay?", “¿En qué consiste?”. A la primera puede contestarse afirmativamente. A las otras dos no puede contestarse ni afirmativa ni negativamente; no tendría sentido preguntar " ¿Qué hay?" o "¿En qué consiste?", y responder "Si" o "No". A la pregunta, "¿Qué hay?" cabe contestar manifestando qué realidades, o qué géneros de realidades, hay; a la pregunta "¿En qué consiste haberlo?" sólo cabe contestar poniendo de relieve la índole de lo que hay.

¿Cuál de estas dos preguntas tiene precedencia sobre la otra? Parece razonable que sea la pregunta "¿Qué hay?", pues sólo después de contestarla declarando lo que haya puede preguntarse " $¿ E n$ qué consiste?", y responder en consecuencia. Pero, zes posible preguntar qué hay si no sabemos en qué consiste, es decir, lo que es? Consideremos una humilde especie animal: Ios conejos. ¿Cómo podemos saber si hay conejos si no tenemos ninguna idea acerca de lo que es "ser conejo"? Invirtamos, pues, el orden de nuestro preguntar y supongamos que hay que saber ante todo en qué consiste algo, sea lo que fuere, pues sólo entonces podremos averiguar si lo hay. Pero, ¿merece la pena preguntar en qué consiste algo si ni siquiera sabemos si lo hay? ¿Cómo podemos saber en qué consiste "ser un conejo" si no hay conejos? ¿Cómo alcanzaremos a conocer lo que son los conejos antes de conocerlos?

Estas vetustas cuestiones son menos temibles de lo que parece. En la práctica - que incluye la práctica de la teoria- no solemos inquietarnos demasiado por esos estatutos de protocolo intelectual. Nos enteramos, por ejemplo, de que hay conejos cuando se nos muestran ciertos animales y se nos dice: "Son conejos". Pronto podemos distinguir entre los conejos y otros animales, y hasta entre los conejos y otros mamíferos. Con sólo modestas dotes de observación, logramos pronto distinguir entre los conejos y otros roedores. No es común, ni necesario, que se nos diga: "Cuando salten a la vista mamiferos del orden de los roedores, de pelo espeso, y a menudo gris, largas orejas y patas posteriores más largas que las anteriores, ahí van conejos." De un modo o de otro sabemos lo que son los conejos, cuando menos hasta el punto de poder identificarlos sin necesidad de aprender los rudimentos de la llamada "historia natural" o de consultar un Diccionario. Cierto que con ello no sabemos todavía gran cosa acerca de los conejos. Saber en verdad lo que son los conejos es historia larga: hay que conocer en qué lugares suelen encontrarse, cómo viven, qué comen, cómo reaccionan ante di- 
versas situaciones, cómo vinieron a juntarse con otras especies en el curso de la evolución, etc., etc. Todo esto, y mucho más, contribuye a darnos una idea cada vez más precisa de aquello en que consiste "ser conejo".

Cosa parecida sucede con respecto a lo que hay, sean conejos o lo que fuere. No reconocemos lo que hay sólo después de habernos estrujado la mollera para saber en qué consiste. Lo reconocemos de inmediato, no, por supuesto, como un tipo, todo lo superior que se quiera, de realidad, sino bajo la forma de "cosas que hay" o de "realidades". Sabemos, así, de muchas cosas que hay antes de saber qué son. En este respecto, la precedencia del conocimiento de lo que hay sobre el conocimiento de aquello en que consiste es todavía más radical que en el caso de los conejos y, en general, de cualquier determinada especie de cosas que haya. Podría no haber conejos, fragmentos de cristal de roca, tempestades, satélites y peces de colores, pero no puede no haber "algo". Ni siquiera es menester que se nos muestre cualquier cosa y se nos diga: "He aquí algo". Vivir es vivir en el mundo, estar entre realidades, "cosas" que hay y, por tanto, "algos" de toda condición y especie. En todo caso, no es menester saber de antemano en qué consiste "ser algo", $\mathrm{y}$, más específicamente, ser algo que hay; ahí está, y consiste justa y precisamente en "estar ah"."

2) Puede comenzarse, pues, sin empacho con la pregunta: "¿Qué hay?". La pregunta es breve, pero la respuesta no lo es. Lo sería sólo si estuviéramos dispuestos a saltarnos todas las dificultades a la torera, y a contestar, por ejemplo: lo que hay es "la Materia", o "el Espíritu", o "la Idea", o "la Percepción", o "la Voluntad", o "el Inconsciente". Pero todo eso sería tanto como no decir nada. Para empezar, los que han dado las respuestas antes registradas las han ofrecido con premeditación, y a menudo con alevosía. Decir que lo que hay es la materia es con frecuencia un punto de partida para un viaje intelectual largo y accidentado. Decir que lo que hay es el espíritu es casi siempre la conclusión de un viaje intelectual no menos accidentado y largo. Hasta ahora, nadie que haya dado respuestas del tipo indicado ha alcanzado ninguna posición en la que haya logrado mantenerse indefinidamente sin temor a ser desalojado. El materialismo, el espiritualismo, el sensacionismo, etc., son posturas tan extremosas como precarias. Pero, además, y sobre todo, aunque las respuestas dadas en cada caso hayan sido argumentadas con profusión, adolecen todas de un defecto capital: el no ser propiamente respuestas a nuestra pregunta. Nuestra pregunta es ontológica, y no física -o siquiera metafísica-; la respuesta tiene que ser también, pues, ontológica. Lo que hay es el dominio de "objetos" -n un sentido muy general de "objetos" - a los que se adscribe realidad, de cualquier índole que ésta sea, material o espiritual, sensible o ideal, etc., etc. Lo que nos interesa, pues, ontológicamente, en lo que hay, es su realidad, no el que sea esto o aquello. A lo sumo, se podría alegar que al decir que lo 
que hay es materia o espíritu, o lo que fuere, contestamos a la pregunta "¿Qué es (o en qué consiste) lo que hay?". Pero no hay tal. Cabe formular esta última pregunta en términos ontológicos, de suerte que requiera como respuesta mostrar la estructura ontológica de lo que hay, sea ello material, espiritual, sensible, ideal, impersonal, personal, o por ventura todas estas cosas a la vez.

La respuesta a la pregunta "¿Qué hay?" no es sólo larga; ante todo, es problemática. Antes de intentar siquiera contestarla, puede interponerse otra pregunta: "¿Tiene sentido preguntar "qué hay'?".

En nombre de la llamada "filosofía del lenguaje corriente", G. J. Warnock ha observado que preguntar, sin más, "¿Qué hay?" no parece cosa seria, porque no hay manera de responder adecuadamente. No por falta de respuestas, sino por exceso de ellas. A la pregunta "¿Qué hay?" puede suceder un número indefinido, $\mathrm{y}$ acaso inacabable, de respuestas: hay montones de nieve; hay en todas partes gentes poco fidedignas; hay en este trabajo ideas muy discutibles; hay poco que hacer; hay escasas posibilidades de que se forme un gobierno estable; hay demasiado ruido; hay todavía esperanza, etc., etc.

Lo primero que se nos ocurre al respecto es que no todos los lenguajes corrientes siguen el mismo patrón. Un análisis gramatical, o filológico, de "Hay" y de sus equivalentes (o supuestos equivalentes) sería asunto largo; basta abrir algunas gramáticas y algunas obras de filología comparada para darse cuenta de que ingresamos aquí en un laberinto. Nos limitaremos a algunos ejemplos. Por lo pronto, los dados en español pueden expresarse de maneras diferentes en otras lenguas; más todavia: algunos pueden expresarse de modo diferente en el propio español. "Hay en este trabajo ideas muy discutibles" puede sustituirse por "Este trabajo contiene ideas muy discutibles" - y no discutamos por el momento si el "contener" es o no un modo de "haber"; en algunos casos puede serlo, pero en otros no lo es. Pero, además, y correlativamente, hay ejemplos en otras lenguas que pueden, y aun deben, expresarse de modo distinto en español. Sin ir más lejos, consideremos dos ejemplos aducidos por Warnock: There is a pen in my hand y There is virtue in necessity. There is se traduce a menudo, y se traduce bien, por "Hay". Pero la mejor traducción de There is a pen in my hand no es precisamente "Hay una pluma en mi mano"; más apropiado parece decir "Tengo una pluma en la mano". Y la mejor traducción de There is virtue in necessity no es precisamente "Hay virtud en la necesidad", sino algo así como "Se hace de la necesidad virtud". Se dirá que, en algún sentido, si tengo una pluma en la mano es porque hay tal pluma en mi mano; y si se hace de la necesidad virtud, es porque hay alguna virtud en la necesidad. Pero no hay necesidad de asesinar un lenguaje para traducir otro. $Y$ no hay virtud alguna en asesinar el propio lenguaje con el fin de seguir manteniendo a toda costa la expresión "Hay" o alguna de sus equivalentes. Un ejemplo de 
las indefinidas formas del "Hay" aducido por Warnock es la frase There is a pain in my ankle. Pero decir en español "Hay un dolor en mi tobillo" no es hablar como Dios manda; es más apropiado decir "Me duele el tobillo". Por lo demás, aunque la frase There is a pain in my ankle sea inglesa, no es la única frase inglesa que cabe armar en esta ocasión; después de todo, puedo decir $M y$ ankle aches, My ankle hurts, My ankle feels uncomfortable, o cosa por el estilo, y todos nos entendemos a las mil maravillas.

Ejemplos sacados de otros idiomas brindan resultados parecidos. Si digo Es gibt einen Gott y se me pregunta cómo puede traducirse esta frase al español, sugeriré, sin vacilar, "Hay Dios" o "Hay un Dios" o "Dios existe" (por lo demás, puedo también decir en alemán, algo más poéticamente, Es ist ein Gott). Pero si digo Es gibt für mich nur eine Möglichkeit y se me pide una traducción al español de esta frase, vacilaré entre "Hay para mí una sola posibilidad" y "Sólo una posibilidad me resta" —con resuelta preferencia por la última-. Der Vortrag ist heute es uno de los varios modos tudescos de anunciar que la conferencia es para hoy. Si se me pregunta "¿Cuándo hay la conferencia?", puedo responder "Hoy hay la conferencia", pero se me concederá que esos "Hay" son bastante ociosos. Bastaría preguntar: "¿Para cuándo la conferencia?", y responder: "Para hoy”. En todo caso, para anunciar que hoy hay, o habrá, tal conferencia, puedo asimismo decir "Hoy se da la conferencia", "La conferencia tendrá lugar hoy", etc. Por otro lado, si bien puedo decir en alemán Heute gibt es einen Vortrag, y en español "Hoy hay una conferencia", puedo asimismo decir Heute wird ein Vortrag gehalten o Heute findet ein Vortrag statt y "Hoy se da una conferencia". Las diferencias entre varios modos de indicar que hay algo son a veces sutiles. Es gibt die merkwürdigsten Vögel indica que hay (en general y dondequiera que sea) los pájaros más notables, mientras que Es sind die merkwürdigsten Vögel indica que hay (en particular y precisamente en el lugar en que se espera que estén) los pájaros más notables. En el primer caso se pone de manifiesto que hay los pájaros de que se trata; en el segundo caso se declara que tales pájaros están ahí. En la medida en que "haber" equivalga a "estar ahí", la diferencia apuntada es de escasa monta, pero podría muy bien suceder que el estar ahí fuese sólo uno de los modos de haber lo que está ahí. En algunos idiomas, como en el ruso, se eliminan a menudo partículas enfadosas; "Hay un libro en la mesa" y "El libro está en la mesa" pueden igualmente verterse al ruso por Kniga na stolé ("Libro en mesa"). Con ello desaparece el "Hay", pero persiste, cuando menos implícitamente, el "ahí está". Sin embargo, el "ahí está" no es suficiente cuando se trata de existencia; con Est li Vog? pregunto, en ruso, si Dios existe (o "es"; an Deus sit); no pregunto, o no pregunto sólo, si Dios "está ahr". En verdad, en este caso no se supone que Dios "esté ahi", porque se supone que "está en todas partes"; su "estar" es un "estar siempre", esto es, un "ser". 
$\mathrm{El}$ asunto es inagotable. Dejo al lector la tarea de forjar frases en francés, portugués, italiano y otras lenguas más o menos familiares; puede también forjarlas en las "lenguas clásicas" que conozca, y sobre todo en las más conocidas entre nosotros: latín y griego. $\mathrm{Y}$ dejo a lingüistas y a antropólogos la faena de practicar análoga operación con el árabe, el hebreo, el chino, el hindi, el turco, el bantú, el quétxua y todos los lenguajes que tengan a bien manejar, sean "primitivos" o "civilizados". Sospecho que si se descubre algo a este respecto, serán variaciones todavía mayores que las apuntadas.

3) Se recordará que Warnock se mostraba algo impaciente con la pregunta "QQué hay?", porque el número de respuestas resultantes podía ser indefinido e interminable. Se habrá visto que su impaciencia era inexcusable. Con sólo ampliar un tanto su horizonte lingǘstico habría advertido que en no pocos casos se puede desterrar el aparentemente omnipresente "Hay...". Que haya copia de There is en inglés no garantiza la misma abun. dancia de "Hay" en español, de Es gibt en alemán, de $I l$ y $a$ en francés, etc. Puede, pues, nuestro autor estar tranquilo; lo único que tendrá que hacer es mudar de vez en cuando de "lenguaje corriente". Y si se resiste a ello se le puede siempre recomendar vigilar atentamente lo que se quiere decir en cada caso cuando se empieza una frase con "Hay..." o alguno de sus equivalentes. Bastará escrutar si con tal frase se contesta o no oportunamente a la pregunta "¿Qué hay?". Muchas frases que empiezan con "Hay..." no parecen, en efecto, responder adecuadamente a dicha pregunta. Así, por ejemplo, no parece que se responda a "¿Qué hay?" cuando se dice "Hay poco que hacer". Tampoco parece que se responda a "¿Qué hay?" cuando se afirma "Hay [hoy, o en este momento] una conferencia". Ni siquiera parece que se conteste a la pregunta en cuestión cuando se declara "Hay un tigre en la casa". En el primer caso no se pregunta, en rigor, "¿Qué hay?", sino más bien "¿Hay o no mucho que hacer?". En el segundo caso tampoco se pregunta en verdad "¿Qué hay?", a menos de subentender que se pregunta algo aś como si hay o no -en el sentido de si se da o no, si tiene lugar o no- una conferencia donde normalmente se espera que se den éstas. En el último caso no se pregunta tampoco "¿Qué hay?" sin más; se pregunta, indíquese o no explícitamente, qué hay en una casa determinada, sospechando que puede haber algo en ella - por ejemplo, un tigre-.

Con ello parece haberse resuelto el problema: no tiene sentido preguntar simplemente " $Q Q u e ́$ hay?", porque o bien las respuestas son indefinidas; o si algunas de ellas noo ló sôn, entonces es porque no se pregunta "¿Qué hay?", sino, por ejemplo, "¿Qué hay en, dentro de, sobre, etc.?". Por estas y otras razones Warnock concluye que la pregunta " $¿ Q u e ́$ hay?" es extemporánea. Lo que cabe preguntar, a lo sumo, es "¿Qué clase de cosas hay?" y, más especificamente, "¿Qué clases de cosas nos comprometemos a creer [o a aceptar] que hay?". 
De este modo se plantea la cuestión del llamado "compromiso ontoló gico" -o, más exactamente, "compromiso óntico"-. Ahora bien, Warnock y otros filósofos del lenguaje corriente no están tampoco bien dispuestos a aceptar este planteamiento; en todo caso, estiman que no se puede solucionar dicha cuestión mediante los criterios elaborados por algunos lógicos y filósofos. Cualesquiera de estos criterios, arguyen nuestros críticos, es pronto desbordado por la variedad y multiplicidad de formas exhibidas por el lenguaje corriente, en el cual se revelan propósitos que no se ajustan a los sentados, explícitamente o no, en los lenguajes científicos. Para quien manipula un lenguaje corriente sin empeñarse en pervertir sus usos -declaran los críticos-, no tiene sentido hablar de lo que hay, ni de cosas que hay, o siquiera de clases de cosas que hay, porque hay muchos modos de entender "Hay...", inclusive cuando se estipulan ciertas condiciones para enunciar correctamente que hay tal o cual cosa. Si se pregunta "¿Qué hay en la mesa redonda?", puede responderse: "Hay una rosa roja". Ahora bien, mientras los lógicos y filósofos aludidos entienden esta respuesta en términos de cuantificación existencial, hasta el punto de que expresan (o simbolizan) del mismo modo "Hay una rosa roja", "Hay algo que es una rosa roja", "Hay por lo menos una rosa roja" y. hasta, si nos apuran "Algunas rosas son rojas" y "Existe una rosa roja", los cultivadores de un lenguaje corriente $\longrightarrow$ de la filosofía en él fundada- estiman que estas expresiones no son equiparables entre sí. Para ser imparciales, habría que llamar la atención de los cultivadores de un lenguaje corriente sobre algunos casos inversos; por ejemplo, ciertas expresiones equiparables entre sí en un lenguaje corriente - tales como "Hay una rosa roja" y "Hay cuando menos y a lo sumo [es decir, exactamente] una rosa roja" - no lo son necesariamente en el lenguaje lógico, cuando menos si para simbolizar la última expresión mencionada se hace uso de cuantificadores numéricos. Pero, excepciones aparte, es cierto que en lógica ( $y$ en ontología) se tiende a poner coto a la variedad e inestabilidad de expresiones del lenguaje corriente, cuyas muy diversas "lógicas" se estima más discreto $\longrightarrow$ más expeditivo— ignorar. Los criterios lógicos y ontológicos siguen siendo, pues, demasiado oprimentes para los filósofos-lingüistas.

4) Antes de seguir adelante, precisaré mi posición sobre estas sutilisimas cuestiones. Tocaré ante todo cuestiones de orden general.

Primero: Los lenguajes corrientes son los instrumentos de que nos servimos para hablar sobre el mundo, para expresar nuestros sentimientos, para comunicarnos con nuestros semejantes. Aunque algunos autores afirman con plausibles razones que es posible en un principio pensar sin el lenguaje, lo normal que es el pensamiento y el lenguaje se hallen estrechamente ligados entre sí hasta el punto de que a veces el deslinde es arduo. En vista de ello, es razonable suponer que el análisis de la "lógica" de ciertas expresiones en 
lenguajes corrientes tiene mucho que enseñarnos. $Y$ como el pensamiento filosófico hace normalmente uso de tales expresiones, sería insensato desdeñar las enseñanzas que pueden desprenderse de dicho análisis. La "filosofía del lenguaje corriente" no es toda la filosofía, pero ninguna filosofía es completa sin que invoque alguna que otra vez el pensamiento que se ha ido depositando lentamente en los lenguajes corrientes.

Segundo: para que fructifiquen las enseñanzas derivadas del análisis de expresiones del lenguaje corriente es conveniente no limitarse a describir usos en uno solo de estos lenguajes. Es muy probable que no todos los lenguajes corrientes sean igualmente ilustrativos, pero en todo caso lo son aquellos en los cuales se ha pensado a fondo filosóficamente. El griego es, por supuesto, un lenguaje ejemplar; sin creer, como Heidegger, que "la filosofía habla en griego", no hay duda que la filosofía ha sido ante todo $\phi\left(\lambda_{0} \sigma o \phi i \alpha\right.$, y que cuando preguntamos "¿Qué es algo?" y, en general, "¿Qué hay?", inevitablemente "formulamos una pregunta originariamente griega". Pero, aunque ejemplar, el griego no es único. En todo caso, la "lógica" de expresiones en el lenguaje corriente es más fructífera cuando se convierte en "lógica" de expresiones en varios lenguajes corrientes.

Tercero: Cuando se trata de escrutar "usos", es impertinente confinarse a los rabiosamente actuales. Un lenguaje no es una construcción estática: es un organismo esencialmente dinámico, que crece... o muere. El carácter dinámico del lenguaje se manifiesta históricamente $\mathrm{y}$, por tanto, los usos actuales pueden, y deben, verse "en" la historia. Además y, sobre todo, junto a los usos llamados "ordinarios", surgen ciertos usos que cabría calificar de "extraordinarios", y que $\triangleleft$ son a menudo los propiamente filosóficos. El pensamiento filosófico no sigue siempre, fiel y ciegamente, al lenguaje; no pocas veces lo conforma, aunque para ello se vea obligada a retorcerlo. Si se pone oldo atento al lenguaje habrá que acostumbrarse a todos sus tonos y no a uno solo de ellos.

Cuarto: los aparatos conceptuales fabricados con propósitos lógicos y ontológicos no se hallan fuera del lenguaje, sino que constituyen uno de sus ingredientes básicos. Es un error creer que tales aparatos sólo sirven para oprimir y estrangular los vastos y diversos "universos lingüísticos" que son los dominios naturales de los lenguajes corrientes. Sirven sobre todo para introducir precisiones sin las cuales muchos de esos "universos" no serfan filosóficamente manipulables. En ciertos casos no puede ni siquiera introducirse alguna precisión sin atentar a "usos" muy corrientes del lenguaje. Pero con ello no se eliminan los "usos" existentes, sino que más bien se producen "usos" nuevos, los cuales pueden inclusive aparecer como "abusos".

Quinto: Prestar la debida atención a sutiles matices de lenguajes carrientes no autoriza todavía a derivar una ontologia de tales matices. La ontología, y en general la filosofía, no tiene, pues, por qué plegarse sin pro- 
testa a los usos, y menos todavía a los usos estimados "normales", de un lenguaje. En primer lugar, la ontología es una teoría de la realidad como tal; consiste en "ver" -reflexiva y, quiérase o no, "especulativamente"las realidades. Por tanto, tiene un fundamento más amplio que los lenguajes corrientes, aun si se supone que hay en el fondo de éstos un denso poso de experiencias. Pero si se considera, o considera también, la ontología como un lenguaje, hay que convenir en que es un lenguaje crítico. Por esta razón no puede desdeñar los "marcos lógicos" en favor de marcos "puramente lingüísticos". La ontología transita de unos marcos a otros sin detenerse en ninguno, pues - como la filosofía entera- consiste en buena parte en un esfuerzo por armar sus propios marcos.

Respecto a mi posición sobre cuestiones de orden más específico, puede resumirse en lo siguiente.

Primero: El número de frases que pueden empezar con "Hay...", o sus equivalentes en otros lenguajes, es por ventura indefinido, pero en la mayoría de los casos estas frases tienen en común el que con ellas se aspira a afirmar que hay "algo", sea lo que fuere. Lejos de asustarnos, esta multiplicidad debe incitarnos, pues ella muestra que la pregunta "¿Qué hay?" puede dispararse en distintas direcciones y con resultados distintos. En principio, pues, no tenemos que preocuparnos por desterrar "Hay...". En vez de recomendar pasarse a otro lenguaje corriente, podemos quedarnos con el que ofrezca mayor latitud.

Segundo: Mis observaciones respecto a la posibilidad de eliminar "Hay..." - - , lo que viene a ser lo mismo, de entender de muy diversos modos tipos de frase que empiecen con "Hay..."- no deben entenderse como expresión del deseo de reducir el aludido número indefinido de respuestas a la pregunta "¿Qué hay?", a un número perfectamente definido. Debe entenderse sólo como un pre-anuncio de que aunque en todos los casos hay "algo", lo puede haber de diferentes maneras. "Hay un tigre en la casa" expresa que un tigre está en la casa. "Hay probabilidades de lluvia" (que, por lo demás, podría expresarse por "Parece que va a llover") indica que hay ciertas condiciones meteorológicas (nubes, vientos, presión barométrica, etcétera) que pueden producir la lluvia. "Hay mucho que hablar" pone de manifiesto que hay muchos asuntos de los que conviene hablar. Lo único que importa es que no se interprete siempre el "Hay. .." como un "Hay... en...". Así, "hay confianza general en el franco suizo" no expresa que haya "algo" que se llame confianza y que se halle "en" el franco suizo; expresa que hay una serie de actos de confianza, manifestados en concretas operaciones financieras, que dan por resultado la firmeza del franco suizo en los mercados internacionales. Por lo demás, "Hay confianza general en el franco suizo" puede expresarse, más idiomáticamente (en español), por "El franco suizo goza de confianza general". Observaré al respecto que en muchos casos las 
"traducciones" de frases que contienen "Hay..." por otras en las que esta expresión queda eliminada representa un claro aviso de que no debe enten: derse siempre "Hay..." como un "Hay... en...", y menos todavía de que no debe entenderse "en" como el hallarse una cosa "dentro de" otra. El "Hay. .." se dice de muchas maneras, incluyendo algunas en las que no interviene "Hay", y otras en las que -como en "Sucede que...", "Pasa que...", "Resulta que...", etc.- parece proponerse un modo, por asi decirlo intermedio, entre ciertas frases con "Hay..." y otras sin él.

Tercero: Los modos como puede enunciarse que hay aquello que se dice que hay pueden hacerse más precisos por medio de un análisis lógico. Tocaré este punto luego con más detalle; por el momento, sólo pondré de relieve que la simultánea aceptación de los muchos sentidos del "Hay..." (aparezca o no esta expresión en la correspondiente frase) en los lenguajes corrientes, y de los sentidos estrictos de "Hay..." dentro de un marco lógico, es paralela a la doble aceptación -expuesta en los puntos Tercero y Cuarto de mis observaciones de índole general- de un número indefinido y posiblemente inacabable de usos en los lenguajes corrientes $y$ de los aparatos conceptuales fabricados con propósitos lógicos y ontológicos. En ambos casos, sin embargo, no se trata de sucumbir a un fácil eclecticismo. Lo que sucede es simplemente esto. Los aparatos conceptuales en cuestión permiten plantear el problema de qué clase de entidades hay y, por tanto, el problema de lo que significa aceptar o no tales o cuales clases de entidades. Pero dentro de este "compromiso ontológico" queda todavía ancho espacio para muy diversas formas de "haber".

Cuarto: Tanto el marco de los lenguajes corrientes como el marco lógico son, sin embargo, insuficientes para dilucidar nuestro problema ontologicamente. En ambos casos se examina cómo puede responderse a tipos de preguntas que podrían resumirse en la cuestión: "¿Qué hay en el mundo?" -donde "mundo" designa todo lo que hay, y donde "en" resume todas las posibles formas de "haber"- En ninguno de estos casos se pregunta "¿Qué hay?" sin más. En ontología, en cambio, esta última pregunta es decisiva. En efecto, con ella se inquiere no qué hay en el mundo, sino qué mundo hay. La pregunta "¿Qué cosas haỳ?" se refiere a realidades que hay, o que se supone que hay; la pregunta "¿Qué hay?" se refiere a la realidad misma. La primera pregunta es óntica; la segunda, ontológica. Todo lo cual no quiere decir que al preguntarse "¿Qué hay?" se inquiera por la realidad, como si se tratara de un "algo" omnicomprensivo, distinto de las realidades y por ventura superior a ellas. En verdad; lo que a menudo se ha llamado "lo que hay" no es independiente de las "cosas" que hay; "lo que hay" es sólo el haber de estas cosas. Por eso me resisto a admitir una distinción tajante entre lo óntico y lo ontológico. El adjetivo "óntico" caracteriza las enti. dades que hay; el adjetivo "ontológico" caracteriza la realidad, es decir, è! 
haber de tales entidades. Es obvio que no las habría si no fuesen reales, pero no lo es menos que no podría hablarse de realidad si no las hubiese - todo lo cual parece cosa enmarañada, pero es simplemente perogrullesca: si la realidad consiste en que haya entidades, en el que las haya se cifra su realidad. En todo caso, puede postularse una especie de "continuidad" entre los esquemas conceptuales ónticos y los ontológicos similar a la que puede observarse entre la estructura de una teoría cientifica y el sistema de conceptos o, si se quiere, de esquemas conceptuales que permiten explicar, aclarar o inclusive fundamentar esta estructura. Las bases conceptuales de una teoría científica no están más distantes de ésta de lo que lo está una teoría sobre las realidades respecto a una teoría acerca de su realidad.

5) Por lo dicho hasta ahora $-y$ también por el modo de decirlo- parece que cuando se trata de preguntas como "¿Qué hay?" y "¿Qué es [o en qué consiste] lo que hay?" lo único pertinente es analizar lenguajes, marcos lingüisticos y supuestos o criterios ontológicos sin tener en lo más mínimo en cuenta lo que se llama "la experiencia".

Aunque brevemente, quiero deshacer todo posible equívoco al respecto. Todo conocimiento ( $\mathrm{y}$ reconocimiento) de realidades tiene su punto de arranque en la experiencia, pero el modo como la experiencia engarza con el conocimiento está lejos de ser asunto diáfano. Por lo pronto, hay diversas formas de experiencia. Aun cercenando, por demasiado discutibles, "experiencias" del tipo de "la experiencia de las esencias", "la experiencia de lo ideal", "la experiencia de los valores puros", etc., quedan todavía la experiencia de la vida, la experiencia histórica, la experiencia artística, la experiencia científica, etc. Pueden denunciarse estas experiencias en virtud de su carácter fluido y vaporoso. Puede intentarse reducirlas a hábitos o a reglas empíricas. En ningún caso son, sin embargo, ficciones: la experiencia de la vida es lo que un ser humano va viendo, sintiendo, sufriendo, etc., en el curso de su existencia, y los esquemas de pensamiento y de. conducta que se va forjando en consecuencia; la experiencia histórica es la serie de costumbres, formas de pensar, modos de sentir, etc., que se han ido constituyendo a lo largo de la historia de una comunidad y que condicionan en gran parte el modo de ser de cada uno de los miembros de ésta; y así sucesivamente.

El asunto resulta algo más claro - pero nunca completamente transparente- cuando (por creerlo así, o simplemente con el ánimo de no complicar demasiado las cosas) entendemos por "experiencia" únicamente la experiencia del mundo físico. Para empezar, hay que ponerse de acuerdo respecto a la estructura de esta experiencia. Para los humanos es la llamada "experiencia sensible" ( $y$ a veces "percepción sensible") en tanto que aprehende -o se juzga que aprehende- inmediata y directamente "lo dado", y en tanto que lo dado consiste $\longrightarrow$ se juzga que consiste- en cualidades como los sabores, los colores, etc. Pero, ¿es éste el único modelo de experiencia del 
mundo físico? ¿No cabría imaginar sujetos no humanos, bien que tan cognoscentes (o más) que los humanos y que usufructuaran otros modos de aprehensión del mundo físico? Martin Gardner ha sugerido la posibilidad de imaginar seres cognoscentes que, en el curso de una evolución biológica distinta de la nuestra, hubiesen adquirido la capacidad de percibir el mundo físico mediante ciertas fuerzas magnéticas o ciertos tipos de radiación que nos son desconocidos. Tales seres considerarían ciertos fenómenos físicos para nosotros inferidos como si fueran realidades "dadas" $-\mathrm{y}$, por tanto, directa e inmediatamente "percibidas" - en tanto que los colores, los sabores y todas nuestras "cualidades sensibles" serían para ellos "entidades inferidas". Sospecho, sin que pueda aducir aquí las razones pertinentes, que todo sujeto cognoscente tiende a estar constituido al modo como lo están los seres humanos $\mathrm{y}$, por tanto, que hay motivos para pensar que la experiencia inmediata y directa (o llamada tal) es la experiencia sensible. Pero aun en el caso de que esta sospecha fuera justa, ello no abonaría la idea de que la relación entre tal experiencia y el conocimiento del mundo físico es simple y unívoca.

La relación sería, en efecto, simple y unívoca, además de ser "directa", si hubiese una serie de elementos básicos dados a la experiencia que pudiesen combinarse hasta formar todos los enunciados posibles relativos al mundo físico. Desde Locke y Hume hasta los atomistas lógicos se han propuesto toda suerte de doctrinas fundadas en el anterior supuesto. Los elementos básicos son, según los casos, las "sensaciones", las "ideas" o los "hechos"; las combinaciones pertinentes obedecen, según algunos, a leyes de asociación psicológica y, según otros, a leyes lógicas. Estas doctrinas son, lo reconozco, muy tentadoras. Si hubiese "elementos experienciales últimos" —como si dijéramos, "átomos de experiencia"-, nada mejor que tomarlos como puntos de partida para justificar y validar, confirmar o refutar, todos los enunciados. Podríamos entonces adherirnos sin temor o bien al atomismo asociacionista o bien al atomismo lógico. En el primer caso tendríamos dificultades para constituir las sensaciones o las ideas en hechos; en el segundo, las tendríamos para justificar la propia noción de hecho. Pero en ambos casos tendríamos un paralelismo entre la experiencia sensible y los enunciados, dentro de la cual nos sería posible encajar la estructura entera de nuestro conocimiento.

Por desgracia, la experiencia sensible no es ni tan elemental ni tan directa como se la pinta; lo que se llama tal es casi siempre un complejo proceso constituido por ia actividad de órganos que funcionan en una no menos compleja trama neurofisiológica, en cuyo marco tienen lugar fenómenos tan complicados como la adaptación, el hábito, etc. En cuanto a los "hechos", sólo son elementales y directos cuando se los toma, más o menos arbitrariamente, como tales, o cuando se supone - lo que para un empirista sería punto menos que pecado capital - que hay algo así como "hechos puros", 
irreductibles a todas las aprehensiones empiricas y constituyendo el fundamento de éstas.

Supongamos, sin embargo, que se hayan vencido todas las dificultades apuntadas y que tenemos, para cada percepción determinada, un determinado enunciado. Con ello no llegaremos todavía muy lejos. Si digo que la tinta con la cual escribo es azul, la percepción de la tinta me mostrará sí es o no azul; si digo que el papel en que escribo es blanco, la percepción del papel me mostrará si es o no blanco. Con los dos enunciados atómicos "La tinta es azul" y "El papel es blanco" podremos formar enunciados moleculares - "La tinta es azul y el papel es blanco"; "Si la tinta es azul; el papel es blanco", etc.-, pero aquí se detiene el proceso. La única conclusión alcanzada es que hay experiencias más o menos sensibles y directas de objetos percibidos o perceptibles. Ahora bien, si digo que la energía electromagnética posee cierta masa, ya no me será posible confirmar (o refutar) este enunciado sólo por medio de una simple experiencia sensible, o sólo mediante una combinación (psicológica o lógica, o ambas a un tiempo) de experiencias sensibles. La confirmación (o refutación) de tal enunciado, y de otros análogos, tiene lugar dentro de un sistema conceptual y, en último término, dentro de una teoría científica. Sin duda que la sola teoría es incapaz de confirmar o refutar el enunciado, pero la sola experiencia no es menos insuficiente. Una teoria puede confirmar o refutar un enunciado cuando éste es derivable de la teoría, pero la teoría no se ha constituido independientemente de los enunciados $y$, a la postre, de las experiencias sensibles. En este sentido sigue siendo válida la idea ya clásica de que un cuerpo de conocimiento, y en particular un cuerpo de conocimiento cientifico, consiste en una combinación siempre inestable, pero nunca totalmente desbaratada, de "hechos" y "teorías" - de "experiencia" y "razón"—. No hay en este respecto ningún "fundamento último" (y menos "único") sobre el cual descanse el peso entero de un cuerpo de conocimiento. A veces se alega que la confirmación o la refutación de un enunciado, o de una serie de enunciados, consiste en una "lectura" de resultados, la cual solamente puede efectuarse por medio de experiencias sensibles, de suerte que por muy complicados que sean los instrumentos de medición, regulación, etc., llega un momento en que no hay más remedio que "leer" las medidas, a cuyo efecto se necesitan, por ejemplo, ojos, es decir, órganos sensibles. Este alegato olvida que la propia "lectura" se verifica dentro de un "lenguaje" que se halla engarzado en estructuras conceptuales sin las cuales la lectura misma resultaría ininteligible. No se trata aquí, por supuesto, de irse al extremo opuesto y de suponer que cuanto se perciba del mundo físico se halla determinado por previas concepciones o por previos "universos lingüisticos" al punto que, como pensaba Whorf, toda experiencia es "experiencia organizada" no solamente dentro de un sistema conceptual determinado - lo cual es cierto-, 
sino inclusive dentro de un sistema conceptual más o menos "arbitrario" (si se quiere, "culturalmente arbitrario") -lo que no es ni mucho menos tan cierto-. La llamada "experiencia sensible" no es un conjunto de "átomos últimos de experiencia", pero no es tampoco necesariamente un flujo caótico y caleidoscópico que pueda organizarse de tantos modos como sistemas conceptuales haya, o pueda haber. Los sistemas conceptuales y los "universos lingüísticos" cortan, o recortan, la realidad según ciertos patrones, pero la realidad no se dejaría cortar, o recortar, tan fácilmente si no se siguieran, como dirfa Platon, sus articulaciones naturales, que son iguales para todos los seres humanos percipientes.

En todo caso, no hay una relación directa, simple y unívoca entre cada percepción sensible y cada enunciado, incluyendo algunos de los enunciados que lo son de percepciones sensibles. Las modos de confirmación, o refutación, de los enunciados sobre las realidades físicas son por ello distintọ según el "lugar" que ocupan tales enunciados en un sistema conceptual y, desde luego, en una teoría. Puede no aceptarse una determinada clasificación de enunciados como la propuesta por Cassirer - según el cual los enunciados que expresan resultados de mediciones físicas son de distinto tipo que los usados para formular leyes físicas, y éstos de distinto tipo que los empleados para manifestar principios físicos, si bien todos ellos están dispuestos a lo largo de una "línea" más o menos continua-, pero es difícil no abrigar la idea de que la relación entre el complejo llamado "experiencia" y el llamado "teoría" no es una relación entre una serie de hechos, A, B, C, y una serie de enunciados $p, q, r$. Un solo hecho puede afectar a un conjunto: de enunciados, y un enunciado afecta normalmente a un conjunto de hechos. La relación en cuestión es, pues, a la vez global y funcional. No es que la teoría sea independiente, ni siquiera relativamente independiente, de los hechos y, en general, de la experiencia. La relación global y funcional que trato de poner de relieve -en muchos puntos semejante al totalismo pragmático de Quine- no independiza la teoría de la experiencia, y viceversa; en rigor, las hace más interdependientes. Ocurre sólo que la interdependencia resultante no tiene el mismo carácter que la postulada por las concepciones radicalmente empiristas del conocimiento.

Si la experiencia, y específicamente la experiencia sensible, puede, ser un punto de arranque para el conocimiento del mundo físico sin por ello cons. tituir el todo de este conocimiento, tanto más sucede ello en el conocimiento óntico y ontológico. La relación entre experiencia y conceptualización es aquí mucho más compleja; es además, si se me permite la expresión, mucho más "flexible". Pero nada de esto quiere decir que se desvanezca toda relación y que, por tanto, la experiencia, incluyendo la experiencia sensible, tenga poco o nada que ver con las cuestiones ónticas y ontológicas. En la dilucidación de estas cuestiones la experiencia sirve como punto de arran- 
que y a la vez como una especie de trasfondo permanente. Lo último se parece mucho a lo que Russell llamó "el robusto sentido de la realidad", sin el cual la filosofía, y a fortiori la ontología, podría degenerar en logomaquia. La experiencia es la encargada de llamarnos al orden cuando nos desmandamos filosóficamente - lo que sucede más a menudo de lo que sería de desear al hacer uso de conceptos transferenciales-; sólo la experiencia puede advertirnos que nos estamos pasando de la raya. Lo hace, por descontado, de un modo todavía más "indirecto" del que tiene lugar en cualquier teoría donde parecen importar únicamente los ajustes y reajustes conceptuales, pero no está nunca totalmente ausente. En ontología no interesan tales o cuales realidades determinadas $\rightarrow$ tal árbol, tal átomo, tal persona-, sino la estructura de las realidades como tales. Hablar, por ejemplo, de individuos no es hablar de tales o cuales individuos; hablar de propiedades no es hablar de tales o cuales propiedades, etc. Sin embargo, lo que se diga ontológicamente acerca de las nociones de individualidad y de propiedad no es indiferente a la experiencia que se tenga de individuos o de propiedades determinadas. Ciertas diferencias, aparentemente "sólo ontológicas", entre formas de individualidad, de propiedad, etc., adquieren pleno sentido únicamente cuando se las relaciona con la experiencia. Asi, la propiedad "ser un hombre" no es del mismo tipo que la propiedad "ser blanco". Se dirá que la diferencia aparece claramente sólo cuando se traduce al lenguaje lógico, y que sólo el análisis lógico permite evitar las confusiones en que las ontologías especulativas han zozobrado. Nada más cierto; no otra ha sido la razón que nos lleva a menudo a considerar atentamente - bien que siempre harto informalmentelos modelos proporcionados por estructuras lógicas. No desdeñamos ni mucho menos las estructuras lingüísticas usuales, pero reconocemos que éstas pueden a veces despistarnos; al fin y al cabo, decimos "es un hombre" y "es blanco" - lo que revela cierta diferencia-, pero podríamos decir respectivamente est homo y est albus - lo que no parece revelar ninguna-. Ahora bien, tanto si toman como modelos estructuras lógicas como si confía en complejos lingüísticos, las investigaciones ontológicas resultan estériles a menos que se orienten en la realidad, y no cabe orientarse en ella sin poder, cuando menos en principio, "experimentarla". En este sentido, las estructuras en cuestión pueden ser "modelos" en un sentido parecido a como se habla de "modelos" en ciertas ciencias. Los "modelos" no son estructuras rígidas a las cuales haya que amoldar los hechos, ni son tampoco hechos purificados y, por así decirlo, "destilados". Un modelo no es la realidad, pero lo es de la realidad. Cómo lo sea, es asunto complicado; baste por el momento reconocer que uno de los modos como puede comprobarse que una estructura puede ser un modelo de la realidad es dando una interpretación que haga verdadera la estructura. En último término, una interpretación capaz de hacer verdadera una estructura es ya un modelo de la realidad. 
La interpretación no puede darse, sin embargo, si no se toma la experiencia - por lo pronto, y para seguir simplificando, la experiencia del mundo físico- a la vez como punto de arranque y como piedra de toque. Se ha hablado de individuos y de propiedades, y se ha acordado que toda dilucidación de ellos como tales se funda en experiencia de realidades que son individuales y de realidades que, siendo o no individuales, pueden fungir de propiedades de las primeras. Sin duda que no hay que perder de vista la distinción fundamental entre la mención y el uso de los signos; en la proposición "Moravia es un novelista" una cosa sería tomar "es un novelista" como predicado de "Moravia" y otra distinta predicar de Moravia el ser un novelista. Pero a menos de vivir en un universo platónico donde no hubiese sino proposiciones como tales, hay que convenir en que la primera de las operaciones indicadas arraiga en la posibilidad de ejecutar la operación segunda, de suerte que "Moravia es un novelista" es verdadero si y sólo si Moravia es un novelista, verdad esta última que requiere la existencia de un sujeto humano cuyo nombre es "Alberto Moravia" y cuya actividad más notoria es escribir novelas. Más aún: la experiencia y sólo ella nos orienta acerca del modo como se dan los individuos. Unos, en efecto, se dan como entidades singulares y otros como lo que Quine ha llamado "realidades colectivas", de las cuales son ejemplos los cuatro elementos clásicos: el agua, el aire, la tierra, el fuego y, en general, "la materia", o, si se quiere, "los materiales" - "materiales" con los cuales se pueden formar individualidades que dejan de ser, por decirlo así, "meramente colectivas", aun cuando no por ello alcanzan a ser puras singularidades. Por otro lado, las cosas individuales no son personas, aun cuando las personas pueden ser asimismo consideradas como individuos. En suma: el análisis ontológico no es independiente de la experiencia, aunque el modo como se confirman o no en la experiencia las proposiciones ontológicas sea distinto del modo como se confirman o no otras proposiciones; la confirmación o la refutación ontológicas no se efectúan a base de tal o cual entidad, pero el ser una entidad tal o cual es un carácter ontológico de esta entidad.

Ha llegado el momento de despejar una ambigüedad. Por un lado, he calificado de "ontológicos" muchos de los problemas aquí planteados -específicamente, todos los problemas para cuyo tratamiento se ha echado mano de nociones tales como "lo que hay", "la realidad", "las entidades realés", etcétera. Este uso del vocablo "ontológico" es, me parece, perfectamente legítimo, y a él seguiré ateniéndome; en este sentido, de lo que aquí se trata es, fundamentalmente, de ontología. Por otro lado, aunque he empleado el vocablo "ontológico" en relación con la pregunta "¿En qué consiste lo que hay?", he recurrido al término "óntico" en relación con la pregunta "¿Qué hay?" -en el sentido de "¿Qué clase de entidades [en la más amplia acepción posible de 'entidades'] hay?". Puede pensarse, pues, que se ha usado "ontológico" 
en un sentido demasiado vago, y que convendría, por lo menos desde ahora en adelante, refinar el vocabulario y distinguir entre "ontológico" y. "óntico".

No lo creo así. No veo inconveniente en seguir usando términos como "ontologia", "ontológico", "ontológicamente", etc., para tratar las cuestiones de que se ocupan estas páginas en la medida en que son cuestiones de "filosofía primera", sin que importen las vías particulares seguidas en cada caso: la vía lógica, la semántica, la epistemológica, etc. Desde este ángulo, la pregunta "¿Qué hay?" es ontológica - como lo son las preguntas “¿En qué consiste ser un individuo?", “¿Existen las entidades abstractas?”, etc., y hasta las preguntas “¿Es 'existir' un predicado?”, “¿Pueden darse significaciones sin entidades significadas?", etc. Sin embargo, es recomendable para mayor precisión hablar de "cuestiones ónticas" cuando nos planteamos problemas relativos a qué tipos de enticlades hay o, más específicamente, cabe admitir que hay. Nada de ello obliga a adoptar una distinción tajante entre "lo óntico" y "lo ontológico", y menos todavía a sancionar la idea heideggeriana de "la diferencia ontológica". En primer lugar, todas las cuestiones de filosofía primera -incluyendo, por tanto, las cuestiones que cabe llamar "ónticas"son, en último término, cuestiones ontológicas. En segundo lugar, el uso del vocablo "óntico" para fines determinados no hace las cuestiones ónticas y las ontológicas mutuamente independientes. Se puede - y aun debe- comenzar con la pregunta “¿Qué hay?" antes de plantearse la cuestión de lo que ello sea, pero desde el momento en que se empieza a contestar la pregunta "¿Qué hay?", se va preparando la respuesta a la pregunta “¿En qué consiste?"; a la vez, saber en qué consiste lo que hay está ligado al conocimiento de lo que efectivamente hay.

La diferencia entre "óntico" y "ontológico" no es, pues, una diferencia real - una diferencia entre realidades-; en ambos casos lo que está en cuestión sigue siendo la realidad. Pero es una diferencia metódica, que resulta harto conveniente y en cierta medida inexcusable. En efecto, sólo si preguntamos "¿Qué hay?" cabe lo que se ha llamado con frecuencia "compromiso ontológico" y a veces "compromiso existencial", pero que debería llamarse, más propiamente, "compromiso óntico". El vocablo "óntico" tiene aquí su más plena, y acaso única, justificación.

Ello no excluye que pueda hablarse asimismo de un "compromiso ontológico", y ello en dos sentidos. Por un lado, en tanto que el término "ontológico" se usa en su sentido más amplio, como vocablo que caracteriza todo lo que afecta a la filosofía primera. En vista de ello, todo compromiso óntico es a la vez ontológico. Por otro lado, en tanto que dicho término se use para tratar la cuestión del haber de lo que hay. En tal caso, puede calificarse de "compromiso ontológico" toda teoría básica sobre la estructura de la realidad. Esta teoría depende de las conclusiones alcanzadas respecto a lo que hay, pero no se deriva pura y simplemente de ellas. Si se admite, pues, un 
"compromiso ontológico", hay que convenir en que es distinto del óntico. Este último es una toma de posición ante la realidad —en vista, claro está, de como la realidad se manifiesta a la experiencia y de los modos como puede elaborarse conceptualmente esta experiencia. El primero, en cambio, es una hipótesis fundamental, que parte de dicha toma de posición y procede a interpretarla. En ambos casos la realidad de que se trata está ligada al modo, o modos, como se habla de ella; además, en ambos casos se usan los que cabria llamar "conceptos transreferenciales". Pero en la ontología stricto sensu se admite sin más lo que se ha dado por sentado que hay - lo que en modo alguno cambia lo que haya o, si se quiere, lo que se haya admitido que hay. Por este motivo es recomendable limitar el uso del vocablo "compromiso" a la esfera óntica, porque sólo en ella nos "comprometemos" propiamente respecto a lo que hay. La ontología stricto sensu es, paradójicamente, más especulativa, pero menos arbitraria que lo que podría llamarse "óntica", pues se ocupa de la estructura del ser real - en particular examinando lo que significa en cualquier caso "ser real"- y no de las realidades.

Antes de atacar la cuestión del compromiso óntico, deseo llamar la aten. ción sobre un hecho curioso: el que el vocablo "compromiso" haya sido usado tanto por pensadores de confesión existencial como por otros de propensión "analítica". La significación que en cada caso tiene dicho vocablo es; por supuesto, distinta. Para unos el compromiso es fundamentalmente de carácter personal, de modo que comprometerse filosóficamente quiere decir incluirse a sí mismo en el pensamiento filosófico, ponerse a sí mismo en cuestión en el pensar, etc.; para otros, el compromiso no es, o no es necesariamente, personal, de modo que comprometerse filosóficamente -ontológicamente $o$, en el vocabulario propuesto, ónticamente- es, sobre todo, decidirse a usar un lenguaje que admita tales o cuales tipos de entidades. Pero en ambos casos se reconoce que la realidad no está simplemente "ahi", lo que llamamos "realidad" es en buena parte o lo que hacemos de ella o lo que decimos de ella. Semejante reconocimiento de la interacción entre la realidad y algún modo de operación sobre ella es resultado de honestidad intelectual más bien que de una voluntad de imponerse a la realidad, siquiera sea por medio del "pensamiento". Ahora bien, sería erróneo creer que en todos los casos, incluyendo en las tendencias más o menos "existenciales", se trata de una manifestación de "subjetivismo" o de una reviviscencia del "idealismo". No lo es especialmente en nuestro caso, en que mantenemos una doctrina de la representación como un "ser acerca de...". Comprometerse ónticamen. te no es producir una selección más o menos arbitraria de ciertos fragmentos de la realidad con fines "personales" o por razones "pragmáticas", pues la realidad no queda necesariamente modificada por el hecho de "comprometernos" respecto a ella. A lo que nos comprometemos es, en efecto, a decir ontológicamente lo que es. 
Siendo el compromiso óntico una parte fundamental de la ontología, compete a ésta en definitiva su formulación y las consecuencias que de la misma dimanen. Ahora bien, aunque la ontología no se deriva de otras fuentes o de otras ramas del conocimiento, como si fuese una mera prolongación de ellas, puede, y aun debe, alimentarse de otras fuentes. Desde luego, está orientada en la experiencia tal como he descrito ésta sucintamente. Se vale también de los diversos modos como han descrito, explicado, y hasta sentido, el mundo las varias actividades humanas resumidas con los nombres de "ciencia", "arte", etc., etc. Echa mano del rico arsenal que puede proporcionar el examen del lenguaje, o de diversos lenguajes. Finalmente, saca, o puede sacar, notable provecho de lo que llamaremos con frecuencia "modelos lógicos". La ontología maneja todos estos materiales críticamente, a la vez que procede, a base de una peculiar "reflexión", a una crítica de sí misma y, en la medida en que puede alcanzarlos, de sus propios supuestos. Ninguno de los citados materiales es, pues, desdeñable, pero ninguno de ellos es suficiente.

La relación entre estos materiales y el análisis ontológico es, por lo demás, compleja, y en no pocos casos ambigua. Sería tarea vana empeñarse en precisar lo que es propiamente ontológico a diferencia de lo que no lo es, o lo es "menos propiamente" - $\tan$ vana como averiguar qué problemas son propiamente filosóficos a diferencia de los que no lo son, o lo son menos propiamente. Al igual que la filosofía, la ontologia se halla, por decirlo así, difusa, y hasta confusa, en la mayor parte de las actividades cognoscitivas. La ontologia se ocupa de problemas que pueden reconocerse con relativa facilidad - problemas concernientes a la realidad, a los modos de ser real, a la existencia, etc. Pero estos problemas no suelen estar bien acotados en una determinada esfera del conocimiento. En rigor, se plantean dentro de muy diversas esferas, hasta el punto de que uno de los modos de reconocer que un problema es ontológico es comprobar que se plantea en esferas muy diversas. Por razones de comodidad y simplicidad conviene las más de las veces tratar la ontología como si poseyera su propia "esfera", pero siempre que se reconozca que tal esfera no es independiente de otras, antes bien se constituye en virtud de cierta interdependencia observadas en todas las esferas. Las cuestiones ontológicas son, en una dimensión importante, cuestiones de principios. Mas estos principios no se descubren ni en la base de todos los saberes ni tampoco en la cumbre de ellos, como si fuesen su culminación y coronamiento. Se descubren más bien al explorarse las siempre elusivas y cambiantes líneas fronterizas entre diversos saberes. Desde este ángulo puede decirse que la ontología no es ni comienzo ni fin, sino constante "intermedio".

6) Las observaciones anteriores son ahora especialmente pertinentes porque ha llegado el momento de poner en marcha la máquina ontológica que hemos estado laboriosamente aparejando. Esto puede hacerse de varias mane- 
ras, de las cuales dos me parecen particularmente apropiadas: r) Empezar con una dilucidación de la realidad $\longrightarrow$ del "ser real"- en términos de los "polos" o conceptos límites que llamaremos "ser" y "sentido", para determinar en qué consiste el ser real; señalar qué entidades, o tipos de entidades, son reales; y precisar el marco dentro del cual cabe entonces enunciar que aquello de que se trata es real. 2) Precisar este último marco para señalar qué entidades, o tipos de entidades, son reales; y determinar en qué consiste el ser real con vistas a una dilucidación de la realidad en términos de "ser" y "sentido". Cualesquiera de los dos modos de proceder es adecuado por la simple razón de que en ambos casos nos las habemos con un "todo ontológico" que sólo por las exigencias de la exposición cabe seccionar, pero donde cada sección complica las restantes. El marco dentro del cual cabe enunciar que aquello de que se trata es real está ligado a una determinada concepción de la realidad, y ésta se halla ligada al mencionado marco. Siendo un "todo ontológico", no puede decirse, pues, que cada sección condiciona la otra en el sentido de constituir su fundamento; es más bien el conjunto de la ontología trazada lo que condiciona el contenido de cada una de sus secciones. Ahora bien, estimo que el procedimiento (2) es el más adecuado por tres motivos: porque es metodológicamente el más manejable y claro; porque se halla más a tono con el lenguaje empleado en estas páginas; y porque evita, en la medida de lo posible, los "desenfoques conceptuales" en que es pródiga la filosofía y, a fortiori, la ontología. Ésta es ya de por sí bastante "especulativa"; conviene, pues, acentuar su aspecto "crítico".

De acuerdo con (2), comenzaré con el marco dentro del cual cabe enunciar que aquello de que se trata es real. Es un marco lógico y especificamente un modelo lógico: el que llamaré con frecuencia "modelo lógico del compromiso óntico".y, para abreviar, "modelo". Por lo ya dicho, se comprenderá que tal modelo no es un fundamento que sirva de base a la ontología ni tampoco un principio del cual quepa derivar la ontologia; es simplemente una sección de tal ontología. Por sí mismo, el modelo es insuficiente -y no sólo este modelo sino todo modelo; si fuese suficiente dejaría eo ipso de ser modelo. Puede preguntarse, sin embargo, por qué se elige un modelo lógico más bien que otro tipo de modelo - por ejemplo, uno fundado en el lenguaje corriente, o bien uno que posea sin más un alcance plenamente ontológico.

Respondo a ello diciendo: i) El modelo lógico nos pone en la pista del compromiso óntico, pero sin forzar nuestra marcha hacia un compromiso perfectamente determinado. Ello se debe a que tal modelo es neutral frente a diversos modos posibles de especificar el compromiso óntico. En efecto, el modelo lógico indica el modo como puede expresarse con toda la precisión apetecible el "Hay...", e indica, por consiguiente, el modo de expresar que hay lo que se diga oportunamente que hay. 2) Sólo un modelo lógico per- 
mite dilucidar la cuestión del compromiso óntico con una dosis suficiente de generalidad.

Las dos razones indicadas están estrechamente imbricadas pero la segunda es particularmente digna de nota. En efecto, no habría razón para restringir el compromiso óntico sólo a entidades que poseen, $o$ a las que atribuimos, un nombre propio, cuando nos es posible incluir tales entidades en variables que abarquen todas las entidades necesarias, sea una sola entidad, sea un número determinado o un número indeterminado de entidades. Consideremos dos ejemplos: "Marte es un planeta del sistema solar" y "6 es un número perfecto". Afirmamos con ello que hay el planeta Marte y que hay el número perfecto 6 -si se quiere, afirmamos que hay las entidades designadas respectivamente por el nombre propio "Marte" y por la cifra "6"Si nos atenemos a estas formulaciones, es claro que resultará harto problemático que podamos hablar de un compromiso óntico. En primer lugar, y sobre todo, se puede hablar de muchas cosas sin pretender siquiera que las haya; de lo contrario, cada vez que formuláramos una proposición tendríamos que admitir que hay aquello de que la proposición trata. En segundo lugar, no nos comprometemos a decir que hay algo si no decimos efectivamente que lo hay, pero no se dice que lo hay a menos que se incluya dentro del dominio de un cuantificador.

Ello abona los dos modos como se ha expresado el compromiso óntico: por medio de la cuantificación existencial y por medio de la generalización existencial. En la primera se admiten las entidades que son valores de variables ligadas; si digo que para algunos $x, x$ es $F$, admito todas las entidades, $x$, que son $F$. En la segunda se traducen a términos cuantificacionales cualesquiera afirmaciones acerca de una entidad particular; si digo que Marte es un planeta del sistema solar, afirmo que hay algo que tiene el nombre "Marte" y que es un planeta del sistema solar, y si digo que 6 es un número perfecto, afirmo que hay algo que es el número 6 y que es un número perfecto. Me comprometo, pues, a admitir planetas (por lo menos uno) y me comprometo a admitir números perfectos (por lo menos uno). Es aproximadamente el criterio óntico tal como lo ha expresado Quine. Decimos que hay $x$ que son $F$ cuando $x$ posee un cierto valor que puede extenderse a todos los objetos que caen bajo su dominio. El valor de referencia es el de la designación. " $x$ " puede no designar nada, en cuyo caso no hay $x$, pero ello no impide seguir hablando de $x$; lo único que sucede es que habrá que afirmar que no es verdad que para algunos $x, x$ sea $F$. No es legítimo decir que hay algo que es nada, pero es pertinente decir que no hay aquello de que se trata $y$, por tanto, es pertinente decir que no es verdad que haya aquello que la variable pretende (sin conseguirlo) designar.

La propuesta de Quine ha sido objeto de innumerables debates. Algunos la han rechazado por considerarla impropia. Otros la han tomado seria. 
mente en consideración, si bien censurándola o por demasiado angosta o por excesivamente neutral. Otros, finalmente, la han sometido a crítica; pero con ánimo de refinarla más bien que de descartarla o de reducir su papel a un nivel prácticamente insignificante. No nos ocuparemos de los que han rechazado la propuesta in toto, porque, desgraciadamente, no han aportado otra en su lugar. En cambio, nos referiremos a varios de los argumentos aducidos por los que, a pesar de todo, han seguido manteniendo la propuesta sobre el tapete, porque nos parece que tal propuesta es particularmente adecuada cuando menos como punto de partida.

Los que han censurado por demasiado angosto el criterio de compromiso óntico propuesto por Quine se han apoyado sobre todo en un análisis del lenguaje corriente, el cual, arguyen, no es legitimo reducir $-\mathrm{y}$ menos aún reducir en cualquier caso- al modelo de la lógica cuantificacional. Así, por ejemplo, Warnock indica que no parece un despropósito pasar de la aserción "Marte es un planeta" a las aserciones "Hay un $x$ tal que $x$ es un planeta" o "Hay algo que es un planeta". Pero tiene todo el aire de un dislate pasar de la aserción "Mnemosine es una musa" a las aserciones "Hay un $x$ tal que $x$ es una musa" o "Hay algo que es una musa", pues justamente no hay nada que sea una musa. Puedo decir, ciertamente, "Mnemosine es una figura mitológica", pero si bien es cierto que Mnemosine es una figura mitológica, no es cierto que haya una entidad real llamada "Mnemosine", de suerte que a lo que nos compromete ónticamente la afirmación de que Mnemosine es una figura mitológica es a lo sumo al reconocimiento de que algunos han tenido la idea de Mnemosine, o hasta han creido que Mnemosine existe, a menos, naturalmente, que convengamos en que Mnemosine "subsiste", pero este remedio es peor que la enfermedad. Por si fuera poco, hay ejemplos que parecen transformar la generalización existencial en un trasunto cómico. Si digo que el asma es molesta, no por ello digo que hay algo que sea molesto; lo que es molesto no es "algo", sino el asma, o el dolor de muelas o el tener que hablar del compromiso óntico. Para terminar (por ahora), y aducir el mismo ejemplo de Warnock, si afirmo que 17 es un número primo, resultará algo chocante concluir que algo es un número primo, y ello no sólo porque de este modo parecen reconocerse entidades abstractas, sino también, y sobre todo, porque ello nos obliga a pecar contra el sentido. La suma de 8 y 9 es el número ${ }_{17}$, que es un número primo, pero si he perdido la cuenta y no me acuerdo del número 17 , no por ello diré que la suma obtenida era "algo". Lo que sucede en la lógica no sucede (o no necesita suceder) en el lenguaje corriente, entre otras razones porque las expresiones que corresponden al cuantificador existencial son demasiado diversas para que encajen en él sin residuo.

Las cosas no mejoran, por lo visto, cuando examinamos lo que le puede pasar al lenguaje corriente en la cuantificación existencial. Supongamos, en 
efecto, que se empieza con ésta arguyendo que nos comprometemos a aceptar las entidades que fungen de valores de variables ligadas. El esquema "Hay $x$ tales que $x$ es una araña" puede traducirse por "Hay arañas". ¿Decimos por ello que las arañas existen? No necesariamente; de hecho, al decir "Hay arañas" no decimos gran cosa si no le agregamos algo más: por ejemplo "en la casa de mi vecino". Desde luego que si no existieran arañas no podría haberlas en casa de mi vecino, pero - arguye Warnock - decir que hay arañas en casa de mi vecino no es lo mismo que decir que existen realmente las arañas. Podemos decir, sin duda, que las arañas existen, pero se puede preguntar si algo puede existir simplemente, en vez de existir en algún contexto, es decir, se puede preguntar si el existir es un predicado posible de las arañas como lo es el tener cuatro pares de patas. La mayor parte de los filósofos que se han atenido sobre todo al lenguaje corriente han respondido que no. Han sostenido, además, que decir "Hay..." no es lo mismo que decir "...existe"; la afirmación de que algo existe pura y simplemente tiene por lo menos dos defectos: uno, que no es un enunciado, sino más bien un enigma, y otro que con ello se recurre de nuevo al desacreditado "algo" ya introducido en el proceso de la generalización existencial.

Se pueden aducir varios argumentos para desbaratar las acometidas reseñadas. Uno de los más frecuentes reza como sigue: el lenguaje corriente se muestra, en efecto, reacio a dejarse estrangular por un aparato lógico, pero ello se debe a que es un lenguaje sumamente vario y suelto, que rompe todas las cadenas. Pero lo que sucede con el lenguaje corriente no ocurre necesariamente con los lenguajes científicos, los cuales son menos sueltos y varios, pero bastante más rigurosos. El criterio propuesto tiene, pues, una aplicación, harto restringida, pero no por ello menos legítima.

Este argumento ha impresionado inclusive a algunos que se han mostrado dispuestos a seguir aceptando el criterio en cuestión como único criterio de compromiso óntico realmente válido; al fin y al cabo, el propio Quine, para quien "la cuestión de los supuestos ontológicos se reduce enteramente a la cuestión del dominio de objetos abarcados por el cuantificador", reconoce que dicho criterio se aplica normalmente a esquematizaciones lógicas de lenguajes científicos, o partes de tales lenguajes, y que ello basta para los fines perseguidos. El problema es ahora, sin embargo, el siguiente: supongamos que el criterio de referencia tenga una validez limitada a ciertos lenguajes. Lo que pueda decirse en otros lenguajes, y especialmente en los lenguajes corrientes, relativo a los modos como se enuncia que tales o cuales entidades existen, ¿será entonces independiente de todo modus dicendi propiamente ontológico? ¿No habrá, pues, ninguna ontología capaz de dar razón de los modos existenciales de decir en los lenguajes corrientes? ¿O habrá dos ontologías distintas e incomunicables: una para los lenguajes corrientes y otra para los lenguajes científicos? 
Aunque reconozco que el criterio propuesto funciona más adecuadamente cuando se trata de lenguajes científicos que de los lenguajes corrientes, me resisto a responder a cualquiera de las preguntas anteriores afirmativamente. Estimo que en todos los casos se puede emplear un lenguaje ontológico dentro del cual sea posible expresar un criterio de compromiso óntico, pero me cuesta aceptar una pluralidad, o siquiera una dualidad, de ontologías mutuamente independientes. En primer lugar, no veo por qué es menester prohijar una distinción tajante entre lenguajes corrientes y lenguajes científicos; dentro de los primeros caben ciertos fragmentos de los segundos, y partes de éstos son expresables por medio de aquéllos. En segundo lugar, la realidad de que tratan de dar cuenta cualesquiera lenguajes formados principalmente por enunciados declarativos (o por enunciados hipotéticos destinados a ser confirmados por enunciados declarativos) es la misma. La física $-\mathrm{y}$, en particular, la microfísica- describe un mundo que no parece tener apenas nada que ver con el universo descrito por el llamado "sentido común" - un mundo que a veces parece "más real" que el dado a la percepción sensible, pero que en ocasiones tiene un aire espectral, evanescente y paradójico- Pero ello no abona la opinión de que hay dos realidades físicas distintas, y hasta opuestas, entre sí: la realidad física es siempre la mis$\mathrm{ma}$, aun cuando se vea, o conciba, de maneras muy distintas. Finalmente, y sobre todo, las cuestiones acerca de ser real y de los modos de ser real son básicamente las mismas para todos los lenguajes y puntos de vista -si más nö, para todos los lenguajes y puntos de vista relativos a uno de los posibles modos de ser real一. La física puede, sin duda, plantear en este respecto problemas de los que la experiencia corriente no tiene la menor sospecha; los conceptos de inercia, interacción, espacio absoluto, tiempo absoluto, etc., desarrollados por la física llamada "clásica", y las nociones de campo, de indeterminabilidad, de complementariedad, de continuo espacio-temporal, etc., etc., de que se ha ocupado la física más reciente proporcionan ideas sobre la realidad física de las que seria disparatado prescindir. Algo semejante ocurre con otras ciencias - como, por ejemplo, las llamadas "ciencias sociales"con respecto a otros sectores de la realidad. Nada de ello significa, empero, que cada ciencia, o siquiera cada lenguaje, posea su ontología particular, no sólo distinta, mas también independiente de las otras. Aun cuando se abogara en favor de las llamadas "ontologías regionales", no habría razón para pensar que cada una de ellas tiene que poseer su propio criterió de compromiso óntico. En rigor, ocurre lo contrario: cada una de tales ontologías se funda en un compromiso óntico previo, el cual se adquiere dentro del marco de la ontología a secas. Si, por ejemplo, se aboga en favor de una "ontología de los objetos ideales", ello será únicamente porque se habrá admitido antes un cierto dominio de objetos calificados de "ideales" - sean éstos lo que fueren-. Si, aun no admitiéndose las "ontologías regionales", 
se incluye entre aquello de que se habla, pongamos por caso, los números enteros, ello será porque se habrá dado la aquiescencia a un compromiso óntico relativo a dichos números, y así sucesivamente. Un compromiso óntico requiere admitir, como algo que hay -como "realidad"-, algún tipo de entidad. El tipo de entidad admitida queda especificado por medio de un lenguaje. Se cae de suyo que en este respecto unos lenguajes pueden ser más adecuados que otros. No es, pues, sorprendente que las ciencias -especialmente las que, cual la matemática y la física, han alcanzado un excepcional grado de desarrollo- gocen de algunos privilegios en este sentido. Sin embargo, ello no excluye otros modos de especificación del tipo de entidad admitida, siempre que tales modos, lejos de estar en conflicto con los anteriores, sean más bien complementarios. Decir en el lenguaje de la física que hay entidades individuales poseedoras de tales o cuales propiedades, presupone una idea de "entidad individual dotada de tales o cuales propiedades" que puede resultar más rigurosa que la idea similar adquirida por medio de la experiencia cotidiana y expresada, o expresable, en alguno de los lenguajes corrientes. Pero en ambos casos se pone de relieve la misma idea de entidad individual -idea que compete a la ontología desentrañar-. Algo análogo sucede con ideas de realidades especificables en otros lenguajes científicos o que inclusive no han sido hasta ahora objetos propios de ninguna ciencia. Consideremos, como ejemplo, nociones de entidades no propiamente individuales, aunque de algún modo individualizables ("entidades" tales como "la ley canónica" o "la conquista del Oeste"). Cualesquiera que sean los lenguajes en los cuales se especifiquen tales "entidades", tienen que ser primariamente objeto de un compromiso óntico, la naturaleza del cual es idéntica en todos los casos. Hay, pues, un modo, y sólo uno, de comprometerse a admitir tales o cuales realidades: es, pura y simplemente, comprometerse a admitirlas.

En vista de todo ello parece que lo más razonable sería echar por la borda lo que he llamado "el modelo lógico" y proceder sin más preámbulos a desarrollar una ontología todo lo menos "especulativa" que se pueda y todo lo más analítica, crítica y descriptiva que se consiga. Ejemplos de este proceder no faltan: los encontramos en muchos de los análisis ontológico-formales llevados a cabo por Husserl; en gran parte del sistema ontológico edificado por Nicolai Hartmann; en la metafísica descriptiva de Strawson; en el examen de diversas cuestiones básicas ontológico-existenciales efectuado por Roman Ingarden; en la ontología analítica bosquejada por Herbert W. Schneider; y en varias ontologías fenomenológicas (o fenomenologías ontológicas), sistemas categoriales, doctrinas de los "modos de ser" y otros esfuerzos similares particularmente abundantes en lo que va de siglo. Todos estos ejemplos son interesantes, y algunos de ellos particularmente convincentes. Estoy, pues, de acuerdo en que hay que desarrollar efectivamente una onto- 
logía, y simpatizo con algunos de los modi dicendi ontológicos propuestos por varios de los autores citados. Sin embargo, sigo insistiendo en que no se puede prescindir del modelo lógico por ser éste el único capaz de situar nuestro problema en un punto equidistante de todo compromiso óntico efectivo. Se ha achacado a veces al criterio propuesto por Quine el ser excesivamente neutral. Ahora bien, aunque admito que lo es (bien que no "excesivamente"), no estimo que ello constituya un inconveniente, sino más bien una ventaja. Sólo un modelo lógico, en principio neutral, permite especificar rigurosamente la naturaleza del compromiso óntico. Por sí mismo, el modelo lógico es insuficiente. Pero sin él no nos será posible ponernos en marcha hacia la ontología perseguida. Para elaborar cualquier ontología, el modelo lógico, y el criterio de compromiso óntico que con él se expresa, es el ineludible punto de partida.

7) Hasta aquí se ha hablado del compromiso óntico como si consistiera en uná sola y simple operación que, una vez practicada, nos pondría al cabo de la calle. Ha llegado el momento de reconocer que el compromiso de refẹrencia es una operación en dos tiempos. En el primero se determina, a base de un modelo lógico, en qué consiste comprometerse ónticamente; en el segundo se especifica el compromiso. En lo que resta de este trabajo llevaré a cabo -o, mejor dicho, terminaré - la primera fase de la operación; en otro trabajo recorreré la segunda fase. Con ello puede verse que la parte central de nuestra ontología consiste esencialmente en los tres siguientes pasos:.1) Determinar el marco dentro del cual se formula la pregunta "¿Qué hay?"?; 2) Responder a esta pregunta; 3) Averiguar en qué consiste lo que hay. Sólo al dar este último paso se procederá a desarrollar las nociones de "ser" y de:"sentido" dentro de cuyo ámbito se explicita la noción fundamental perseguida: la de realidad.

El:modelo lógico adoptado para expresar la naturaleza del compromiso óntico es el que echa mano del cuantificador existencial: "Para algunos (cuando menos un) x...", "Hay. .. x..."; en sírnbolos " $(E x)$ (..x...)" Las variables cuantificadas quedan, así, ligadas, de suerte que el alcance del compromiso es el de la variable, o variables, ligadas correspondientes. Como ha indicado Church, el uso de la variable antecede el del nombre, porque el compromiso óntico afecta a entidades de una cierta categoría más bien que una entidad particular determinada. Pero al anteceder el de cualquier nombre incluye a la vez el nombre. La variable usada es con frecuencia resultado de una generalización existencial, como cuando se dice, por ejemplo, "Júpiter es un planeta" y se generaliza existencialmente afirmando "Hay aígo que es un planeta"; en símbolos “( $E x) P x$ ". Así, nos comprometemos ónticamente a aceptar $x$, que es tal y cual (por ejemplo, un planeta), cuando $x$ funge de variable existencialmente cuantificada en una fórmula del cálculo cuantificacional (o funcional). 
Se cae de suyo que no basta cuantificar para que haya las entidades abarcadas por el cuantificador. La lógica no hace milagros. Se limita a indicar de qué modo se expresa lógicamente el "Hay..." o el ". . existe" -que, por el momento, usaremos como si fuesen expresiones sinónimas. Así, por ejemplo, si cuantificamos existencialmente un $x$ tal que $x$ es una esmeralda, nos comprometemos ónticamente a aceptar que hay esmeraldas. Puede ocurrir que no las haya, pero aun en este caso seguimos echando mano del cuantificador. Decimos entonces que no hay un $x$ tal que $x$ sea una esmeralda $\longrightarrow$ también que ningún $x$ es una esmeralda-. Lo que importa, pues, aquí es el modo como se dice que hay (o que no hay) aquello de que se trata. No decimos, en efecto, que se trata o no de esmeraldas, porque justamente se trata de ellas, pero decimos que las esmeraldas de que se trata son algo que hay o que no hay. La fórmula lógica del compromiso óntico nos compromete, pues, con respecto a la noción de existencia; cuando negamos la existencia negamos la existencia, pero no otra cosa distinta de ella. De una fórmula lógica no se puede derivar, o inferir, ninguna realidad, pero el reconocimiento y el no reconocimiento de realidades se expresa, por lo pronto, mediante tal fórmula.

Puesto que los cálculos cuantificacionales pueden ser de varios órdenes, se ha planteado a veces el problema de si el compromiso óntico es expresable únicamente dentro del cálculo cuantificacional (o funcional) de primer orden -donde se cuantifican variables individuales - o bien si cabe expresarlo, o expresarlo asimismo, dentro de cálculos de órdenes superiores, y en particular dentro del cálculo de segundo orden -donde se cuantifican, o cuantifican asimismo, variables predicados.

Respondo diciendo que el compromiso óntico es tal justamente porque su expresión lógica consiste en cuantificar variables y, por tanto, no hay, en principio, límites en las variables, o tipos de variables, que pueda abarcar el cuantificador. Otro asunto es si cabe cuantificar exclusivamente variables no individuales. No parece que sea necesario. En efecto, en fórmulas como " $(E F)(F x . F y)$ ", que puede leerse "Tanto el corcho como la madera flotan en el agua" se cuantifica la propiedad "flotar en el agua" en cuanto propiedad común a dos substancias materiales. Si la fórmula es verdadera, resulta de ello que flotar en el agua es una propiedad real, en cuyo caso parece inevitable, o si más no razonable, admitir que hay algunas substancias (por lo menos dos) que flotan en el agua.

Obsérvese, sin embargo, que en dicha fórmula se ha cuantificado " $F$ ", pero no " $x$ " y " $y$ ". Por tanto, sólo " $F$ " aparece como variable ligada; no asi " $x$ " $y$ " $y$ ", que aparecen como variables libres. Con ello quedan: fuera del compromiso óntico. Podemos decir a lo sumo que hay la propiedad "flotar en el agua" sólo si hay alguna entidad que tiene esta propiedad o, de dos entidades distintas si hay estas dos entidades distintas -0 , hasta en 
último término, que es una propiedad de dos tentidades distintas si es posible que haya estas dos entidades distintas-- No decimos, sin embargo, que lo único que hay son propiedades. Puede alegarse, sin duda, que si una propiedad es una cualidad, no hay inconvieniente en aceptar un universo compuesto exclusivamente de propiedades. Tal sería el tipo de universo en el cual no se admitiria ninguna entidad excepto en la medida ien que estuviese constituida por lo que se dice de ella - lo que equivale a afirmar que, en puridad, no habría entidades, sino sólo lo que se ha llamado "haces de pro piedades" o, en términos existenciales, "haces de cualidades". No habria, pues, en tal universo un $x$ que flotara en el agua, fuese verde, girara en torno a su eje, formara parte de un campo electromagnético, etc., sino únicamente un "compuesto" de algunas de estas "propiedades" o de todas ellas. El $x$ no sería solamente "un no sé qué", justamente porque por sí mismo no sería nada. Pero ello crea una situación un tanto embarazosa para salir de la cual parece que no nos queda más remedio que adherirnos a una de las dos tesis siguientes: o considerar tales propiedades como generales por ser comunes a varias entidades, o bien hacer de las propiedades un "aquí y ahora flotar en el agua", "aquí y ahora verde", etc. En el primer caso, adoptamos una posición determinada en la llamada "disputa de los universales" que es mejor reservar para otra ocasión. En el segundo caso, hacemos de las propiedades un $x$ que llamamos "aquí y ahora flotar en el agua", "aqui y ahora verde", etc., lo cual nos lleva a preguntarnos si no sería mejor considerar cada una de las "cualidades" expresada por la propiedad cómo un "algo" y, por tanto, como una variable individual - lo que supondría alterar la fórmula inicial.

Puede argüirse que no hay un solo tipo de variables predicados. De algo se puede decir que flota en el agua, pero también se puede decir de algo que es, por ejemplo, un hombre. Así, una fórmula como " $(E H)(H x \cdot H y)$ " puede leerse "Tanto los chinos como los rusos son hombres". En este caso parece que enunciamos algo ónticamente más fundamental o, por lo menos, más interesante que cuando decimos "Tanto el corcho como la madera flotan en el agua". Sin embargo, no decimos todavía que haya algo que sea un hombre; o si los rusos y los chinos son hombres, no decimos que haya rusos ni chinos. Si hay rusos y chinos, y si son hombres, entonces hay hombres. Pero a menos que se cuantifique existencialmente el "algo" del que se dice que es un hombre, no habrá compromiso ontico respecto a hombres.

No vale argüir que puiesto que nada podría ser nada determinado si no lo hubiese, al aceptar el ser algo determinado aceptamos a la vez algo de lo que decimos que es tal o cual cosa determinada. Si el algo en cuestión no son hombres, se dirá, serán mariposas, satélites artificiales o quién sabe "qué" - pero un "qué" nadie, al parecer, se lo quita. Pero justamente este "qué" es lo que el hipotético "algo" es, o se supone que es, pero no 
es el. "algo mismo" que lo es. Ahora bien, en ontología nos interesa justamente este algo que es - sea lo que fuere. Por supuesto que nada sería si no fuese algo, y especialmente algo que lo constituye como tal. Por esta razón, al cuantificarse existencialmente letras argumentos, éstas van acompañadas de predicados. Primariamente, no se dice que hay algo, sino algo que es: tal y cual. Si no fuera tal y cual no sería nada. Pero para ser tal y cual tiene que ser alguna cosa. Reconozco que en este punto parece haber un conflicto entre el lenguaje lógico y el ontológico - conflicto en nuestro caso tanto más penoso de admitir cuanto que hablamos, por lo menos para empezar, ontológicamente a base de modelos lógicos. Como ha indicado W. H. Schneider, "algo" como tal -es decir, algo, "sea lo que fuere"- es lógicamente vacío, y en este respecto cabe comparar "algo como tal" con cualquier nombre propio, siempre que desnudemos a éste de toda posible significación. En ambos casos, en efecto, no se dice nada. Sin embargo, la ontologia no tiene más remedio que apechugar con los problemas que plantean tanto los nombres propios vaciados de toda significación como, y sobre todo, las expresiones que, como "algo como tal", no parece que puedan jamás tenerla. Por lo pronto, seguiré haciendo aquí uso de expresiones en las cuales intervienen simbolos que designan, o aspiran a designar, algo que es tal.y cual, o se componen de tal o cual manera. A más no alcanza el compromiso óntico. En cambio, la dilucidación ontológica que seguirá oportunamente tomará en serio la cuestión de la posibilidad de.tratar de "algo como tal"; en efecto, el ser "algo", independientemente de lo que sea, es lo que constituye justamente su realidad. El compromiso óntico afecta a cosas que hay $-y$ que hay justamente porque son, o pueden ser, aquello que se dice que son, o pueden ser. La fase más propiamente ontológica de la presente investigación no puede prescindir de las cuestiones ónticas, pero su fin último es el problema de la realidad o, una vez más, el del "haber" de lo que hay.

A riesgo de reiterar ocasionalmente algunos puntos ya dilucidados, afrontaré de inmediato varias de las cuestiones que se han suscitado con respecto al modelo lógico propuesto. Estas cuestiones son las siguientes:

A) Puede todavía ponerse en duda y, por tanto, preguntarse si hay que recurrir necesariamente a un modelo lógico para expresar la naturaleza del compromiso óntico, o si no cabría echar mano de otro modelo, especialmente de uno que resultara, como se reclama a veces, "más flexible", y que fuera sobre todo capaz de abarcar modos no estrictamente lógicos de expresar el compromiso en cuestión.

B) El modelo lógico es de naturaleza cuantificacional, pero cabe todavía preguntar a) si no hay otros modelos lógicos posibles, y $b$ ) aun suponiendo que no los haya, si todo modelo cuantificacional del tipo indicado acarrea consigo un compromiso óntico. 
C) Aunque el modelo adoptado es, en sustancia, el propuesto por Quine, cabe averiguar si es susceptible de modificaciones.

Trataré de responder a todas estas cuestiones, advirtiendo solamente que, por ser nuestro interés primariamente ontológico, tocaré los aspectos lógicos sumaria, somera y, desde luego, llanamente (esto es, no. "formalmente").

A) Me he ocupado ya de esta cuestión en otro lugar. Agregaré aquí que si bien no están excluidos en principio modos de presentar la naturaleza del compromiso óntico distintos de un modelo lógico, el hecho es que, como ha puesto de relieve Church, estas otras formas están por ahora nonnatas. A esta razón de carácter pragmático puede añadirse otra menos ad hoc: cualquier otra forma "pre-lógica" y "pre-sistemática" de presentar la naturaleza del compromiso óntico es susceptible de encajar dentro-de un modelo lógico donde adquiera toda la precisión requerida. Ocurre a este respecto algo similar a lo que sucede con la relación entre experiencia prepredicativa (o ante-predicativa) y juicio, de que ha hablado Husserl. Puede muy bien suceder que el juicio se halle orientado por la experiencia, la cual entonces "condiciona" en cierto modo el juicio y no a la inversa. Ello no le impide al juicio poder "abarcar" la experiencia pre-predicativa en el sentido cuando menos de hacerla explícita. Similarmente, un modelo lógico puede muy bien "abarcar" y hacer explícitas formas "pre-lógicas" y "pre-sistemáticas", aun en el caso de que éstas condicionen y orienten el modelo lógico y la interpretación dada al mismo.

La opinión que mantengo al respecto difiere de la de quienes se niegan a recurrir a un modelo lógico fundándose en su inadecuación y penuria con respecto a las formas más o menos exuberantes de los lenguajes corrientes, y ello en dos sentidos.

Por un lado, si se trata de buscar una capa más fundamental que la de las estructuras lógicas con el fin de enraizar en ella la noción de existencia $y$, en último término, de "lo que hay", lo mejor es no quedarse a mitad de camino. Por debajo de los lenguajes corrientes (bien que amasadas con éstos) se encuentran las "experiencias de la realidad" forjadas en el trato con ésta. De estas experiencias brotan especulaciones que se expresan, por lo pronto, en algún lenguaje corriente, pero que no pueden satisfacerse totalmente con éste. Si los lenguajes corrientes bastaran para expresar supuestos existenciales, habría que convenir en que tales supuestos serían tan diversos como lenguajes o, si más no, grupos básicos de lenguajes corrientes hubiese: la idea de realidad sería tan distinta en lenguajes indoeuropeos de lo que es en otros lenguajes -semíticos, mongólicos, etc.-, que cabría dudar que se trata en todos los casos de lo mismo. Lejos, sin embargo, de dejarse arrastrar por los lenguajes corrientes, los filósofos han solido romper con frecuencia sus barreras. Así la ausencia en los lenguajes semíticos del verbo 
auxiliar "ser" no impidió a los pensadores árabes forzar su propio lenguaje. Según varios especialistas (A.-M. Goichon, Schell M. Afnan), los árabes sortearon la dificultad apuntada usando, para expresar "ser" (esse), el término wujud, que es la forma pasiva correspondiente al vocablo kama, el cual significa "existencia" en el sentido de "encontrarse, o estar, en tal o cual posición o situación". Wujud expresa entonces el esse en cuanto que "ser encontrado" o "encontrarse existiendo". Por medio de artificios análogos, los lenguajes filosóficos se hacen mutuamente "traducibles". Ello resulta indispensable en filosofía y, a fortiori, en ontologia, donde la traducibilidad no es un mero desideratum lingǘstico, sino también, y sobre todo, una condición de inteligibilidad. En este sentido, la conceptuación ontológica precede a cualquier otra, incluyendo la expresada, o expresable, en lenguajes corrientes.

Por otro lado, el descontento a veces manifestado ante los modelos lógicos se debe a que se desconoce su función y a que, paradójicamente, se espera de ellos más de lo que pueden proporcionar. Pero un modelo lógico como el que tenemos en vista no es un principio del cual se puedan derivar enunciados ontológicos; es sólo una estructura formal dentro de la cual cabe formular tales enunciados. El modelo lógico del compromiso óntico sólo compromete a una cosa: a especificar el "...que es..." en el sentido del hecho de que sea. No dice, ni tiene por qué decir, qué es en el sentido de indicar cuál es. Menos todavía dice en qué consiste que sea -en suma, en qué consiste su realidad o su "haber"- El modelo lógico permite enunciar sin ambigüedad que hay algo, y especifica, o formaliza, el modo de aceptarlo. La ventaja capital de esta especificación es que permite unificar los lenguajes corrientes para propósitos ontológicos. Los lenguajes corrientes no son totalmente innecesarios; como veremos oportunamente, un examen del sentido de "Hay..." arroja no escasa luz sobre el que algo sea, pero esta luz debe ser enfocada por medio de un modelo lógico si se quiere evitar, entre otros resultados, que haya tantas "ontologias" como lenguajes corrientes, o tipos de lenguajes corrientes. Por supuesto que hay varias "ontologías" posibles, pero su posibilidad tiene que mostrarse por medio de una conceptuación ontológica, la cual obliga con frecuencia a modificar los modos de decir en los lenguajes corrientes.

$B$ ) Una respuesta apropiada a esta cuestión nos llevaría muy lejos. Por fortuna, bastan para nuestro propósito algunas observaciones a la carrera.

No es necesario detenerse mucho en modelos lógicos que pueden resultar menos "neutrales" que el propuesto, pero que, en todo caso, hacen uso de la cuantificación de variables para el propósito perseguido. Tal sucede cuando se ha propuesto (Leonard) formalizar el concepto de existencia (en nuestro caso, equiparable por el momento al "Hay...") no solamente como existencia singular, sino también como existencia general -o existencia de 
las llamadas "propiedades"- - Según hemos visto antes, la cuantificación puede funcionar en este caso de modos distintos: para formalizar la noción de existencia singular se cuantifica la propiedad que se supone caracteriza el individuo, y para formalizar la noción de existencia general se cuantifica el individuo que exhibe (o, en última instancia, puede exhibir) la propiedarl de que se trate. Lo importante aquí sigue siendo, en efecto, el proceso de la cuantificación.

En cambio, puede suscitar algunas dudas el reconocimiento (Allan Ross Anderson) de otros modelos lógicos -específicamente, los cálculos de conversión lambda - capaces de contener nombres de entidades - si más no, nombres de algunas de las llamadas "entidades abstractas", tales como los números enteros. Algunas de las expresiones en estos cálculos pueden definirse de tal suerte que funcionen como cuantificadores (existenciales). Por tanto, no parece que sea indispensable atenerse exclusivamente a los modelos cuantificacionales ya familiares.

Sin embargo, este hecho refuerza, más bien que debilita, la noción de cuantificación existencial para expresar la naturaleza del compromiso óntico. En efecto, si hay expresiones en un cálculo que funcionan como cuantificadores existenciales, son sin más tales cuantificadores; no hay diferencia esencial entre exhibir las características de un modelo cuantificacional y ser este modelo. Por tanto, más bien que hablar de "otros cálculos distintos del cuantificacional", cabe hablar de la cuantificabilidad de otros cálculos. Al fin y al cabo, también en cálculos con expresiones de longitud infinita cabe cuantificar un número infinito de variables. A la postre, pues, nos quedamos reducidos a un modelo cuantificacional, por lo que conviene mejor considerar uno que lo sea ya desde el primer momento, y que pueda servir como pauta para comprender los demás, en vez de otro que pudiese, en algunas de sus expresiones cuando menos, fungir de tal.

Más delicada es la cuestión de si el modelo cuantificacional acarrea necesariamente un compromiso óntico. Se sabe que se pueden introducir en el lenguaje términos singulares que no designen ninguna entidad particular, ni siquiera dentro de condiciones especificadas (tales como, por ejemplo, un determinado periodo de tiempo), sin por ello producirse ninguna catástrofe, sea ontológica, sea lógica, o ambas. En efecto, el lenguaje no tiene únicamente una función descriptiva; cuando nos preguntamos si hay algo determinado supuestamente designado por un término singular, o cuando postulamos que lo hay sin saber todavía si lo hay, usamos sin empacho tér. minos singulares no designativos. ¿Sucede lo mismo cuando se eliminan términos singulares y se forjan expresiones que se enuncian en términos de variables ligadas? Aparentemente, si se trata de variables ligadas, hay que admitir los correspondientes valores y, por tanto, comprometerse ónticamente con ellos en el sentido ya sugerido. Sin embargo, ello presupone que se 
opera con un sistema cuantificacional que contiene supuestos existenciales -más aún, que si es un sistema cuantificacional en el que intervienen cuantificadores existenciales, tiene que contener tales supuestos. 'Tal presuposición no es en modo alguno necesaria. Jaakko Hintikka ha propuèsto un sistema de teoría cuantificacional sin supuestos existenciales, los cuales, por lo tanto, no están en modo alguno ligados al uso de los cuantificadores. En vista de ello, puede concluirse que no todo modelo cuantificacional acarrea consigo un compromiso óntico.

Una vez admitido lo anterior, sin embargo, hay que tener en cuenta dos cosas. Primera, que los supuestos, o falta de supuestos, existenciales de que se ha hablado conciernen primaria, si no exclusivamente, a los términos singulares. Segunda, que la posibilidad de edificar una teoria cuantificacional sin supuestos existenciales no significa en modo alguno que el compromiso óntico no pueda expresarse en términos cuantificacionales. En rigor; una teoría cuantificacional sin supuestos existenciales puede constituir el marco lógico más adecuado para la introducción de un compromiso óntico fundado en la generalización existencial. Esto parece un tanto paradójico, pero no lo es cuando se considera nuestra tercera cuestión.

C) La respuesta a esta cuestión es decididamente afirmativa. En la aludida propuesta de Hintikka, se modifica la teoría cuantificacional de tal suerte que pueda encajarse en ella una expresión del tipo " $a$ es un valor de una variable ligada", expresión que constituye una explicación (lógica) de "Hay $a$ " - donde " $a$ " se refiere en ambos casos a una entidad particular. Sin entrar ahora en detalles, la modificación propuesta permite introducir fórmulas como " $(E x) \quad(x=a)$ ", en donde transparece que la entidad designada por " $a$ " es idéntica a uno de los valores de la variable ligada designada por " $x$ ". Con fórmulas como la que se acaba de introducir se pzede, según Hintikka, sacar a relucir la diferencia lógica entre lo que es y lo que no es -0 , en nuestros términos, entre lo que hay y lo que no hay. Por su lado, Church sugiere reformular el criterio de compromiso óntico propuesto por Quine como sigue: "La afirmación de $(E x) M$ comporta un compromiso ontológico óntico respecto a entidades $x$, tales que $\mathbf{M}$, donde ' $a$ ' puede ser sustituida por cualquier variable, ' $x$ ' puede ser sustituida por cualquier nombre de la misma variable, ' $M$ ' puede ser sustituida por cualquier forma proposicional que no contenga otra variable libre sino esa misma, y ' $M$ ' puede ser sustituida por cualquier nombre de la misma forma proposicional." Se podrían introducir otras modificaciones, sea para reformu. lar el criterio de compromiso óntico de modo más adecuado, sea simplemente para definir el compromiso óntico en cualquiera de sus formulaciones mediante un metalenguaje semántico. Puede asimismo distinguirse (R. M. Martin) entre criterio de compromiso óntico y criterio de compromiso conceptual. Finalmente, puede intentarse hacer frente en el compromiso óntico 
a conceptos de clase, ya sea para formular un criterio adecuado al respecto, sea para admitir solamente variables que tuviesen un alcance no vacío. No es nuestro propósito entrar en terreno puramente formal. Lo único que nos interesa poner de relieve es que sean cuales fueren las modificaciones introducidas la función de un criterio de compromiso óntico como el aquí aceptado es siempre la misma: precisar el modo como se expresa la noción de existencia independientemente de las entidades, o tipos de entidades, de las que se afirma que existen.

Se ha alegado a veces que el modelo de referencia es válido sólo dentro de condiciones claramente especificadas. No me parece un alegato muy convincente, pues no hay razón para que el lenguaje ontológico no funcione dentro de condiciones claramente especificadas, o especificables. Sin duda que, como se ha visto antes, ciertas expresiones en el lenguaje corriente -o en ciertos tipos de lenguajes corrientes - no encajan cómodamente dentro del modelo lógico. Aparte los casos ya reseñados, hay muchos otros que podrían aducirse a tal efecto. Desde el punto de vista ontológico, el modelo lógico gira firmemente alrededor de dos ejes: "Hay..." y “...algo...". Es fácil desentrañar las ambigüedades de "Hay..." - aun cuando también hay en "Hay...", como veremos a su tiempo, mucho que no es mera ambigüedad-. En cuanto a "....algo...", no se han terminado aún las largas tiradas denunciándolo como un inadmisible afán de simplificar los muchos modos como funcionan ciertos términos en el lenguaje corriente. "Algo" no funciona necesariamente de la misma manera que un nombre propio o que un pronombre demostrativo, y cada uno de estos dos últimos funciona de distinta manera que el otro. Mientras ciertas expresiones son usadas simbólicamente, otras son usadas "sugestivamente". Algunas expresiones funcionan dentro de un contexto extralingüístico, en tanto que otras funcionan dentro de un contexto intralingüistico. Etc., etc., etc.: no habría espacio suficiente aquí para dar cuenta siquiera de la mitad de lo que se ha dicho para demostrar que el criterio lógico del compromiso óntico simplifica a derecha y a izquierda y da al traste con los innumerables matices que se descubren en un lenguaje corriente $-y$ no digamos en todos los lenguajes corrientes si se pudieran examinar con el mismo detalle con que se han escrutado un par o tres de ellos-. Ahora bien, no estimo necesario refutar punto por punto, y ejemplo por ejemplo, las alegaciones hechas, y ello por una razón muy sencilla: porque no son pertinentes. No tienen en cuenta, en efecto, lo que se aspira a hacer con el modelo lógico, y, sobre todo, no parecen advertir lo que no se aspira a hacer con él.

El modelo en cuestión aspira solamente a precisar el status existencial de aquello que se dice que hay. Hay, por supuesto, muchos modos de afirmar o negar, y muy distintos contextos lingüísticos dentro de los cuales se puede afirmar o negar. Pero aquí se trata únicamente de ver lo que se hace 
cuando se afirma o niega que hay aquello de que se trata. Podemos decir, que $x$ es una rosa o que $x$ es rojo, pero en ninguno de estos casos ponemos de relieve el status existencial de $x$. Tal status es expresable, en cambio, por medio del cuantificador, el cual se limita (lo que no es poco) a decir "Hay...". Se puede alegar que si decimos que $x$ existe, entonces decimos que hay $x$. Pero con ello no hacemos sino afirmar que hay un $x$, y el modo propio de afirmarlo es justamente cuantificar $x$. El $x$ es ni más ni menos que aquello que se dice que hay. Como se ha dicho ya que lo hay, no es menester, por supuesto, repetir que existe - por lo menos en tanto que por el momento equiparamos "... existe" a "hay...". Ello equivaldría, en efecto a decir que hay un $x$ tal (o hay algo tal) que existe, lo que no merecería tantas palabras. Al expresar el status existencial de $x$ afirmamos, en efecto, no sólo que hay $x$, sino también de qué $x$ puede tratarse. No podemos simplemente comprometernos a aceptar "algunas cosas que..."; aceptamos algunas cosas que son tales o cuales. Si en el lenguaje corriente nos limitamos a afirmar que hay tales o cuales cosas, ello basta. Pero traducida la correspondiente expresión al lenguaje lógico siempre resultará que lo que se dice es que hay no simplemente algo, sino aquello que se dice que hay. En suma, no se puede acusar al modelo lógico de pecar por exceso, porque lo único que hace es expresar la noción de existencia $\longrightarrow$, en nuestro vocabulario, la noción "Hay..."-.

Se pucde, en cambio, acusar al modelo lógico de pecar por defecto, pero ésta es una acusación que acepto de muy buen grado. Por ejercer la función que ejerce, el modelo lógico se limita a decir que algo (sea lo que fuere) es $\longrightarrow$ lo hay-. No dice ni siquiera qué entidades, o tipos de entidades, hay. Es cierto que mediante el modelo lógico nos comprometemos a aceptar tales o cuales entidades, pero ello es muy distinto de decir que el modelo lógico nos compromete a aceptar tales o cuales entidades. El aceptar tales o cuales entidades, o tipos de entidades, depende justamente de que se incluyan dentro del modelo lógico. Para evitar confusiones convendría acaso distinguir entre el criterio lógico del compromiso óntico y este compromiso, el cual se expresa por medio de dicho criterio, pero no consiste en tal criterio. En otros términos, cada vez que se dice que hay tales o cuales entidades, se admite implícitamente la forma adoptada por el criterio lógico del compromiso óntico, pero no se dice que hay tales o cuales entidades porque dicho criterio per se no obliga a aceptarlas.

Concluiré afirmando que el modelo lógico expresa el que -n el sentido del algo que hay-, y que mediante el modelo lógico se puede expresar el qué —en el sentido de qué entidades hay, o cuáles son estas entidades. Pero la razón por la cual se expresa qué o cuáles entidades hay no está en el modelo lógico. De éste no puede derivarse una ontología; a lo sumo, se puede expresar con él lo que es básico en toda ontologia: la noción de "Hay...". 
De qué se deriva entonces dicha ontología, es cuestión nada liviana, porque está ligada al problema de la posibilidad de toda ontología. Arriesgaré aquí, para terminar, algunas observaciones.

Por lo pronto, no hay que suponer que un sujeto cognoscente, y específicamente un sujeto humano, posea ninguna facultad especial que le permita habérselas directamente con la realidad en cuanto realidad. No hay, pues, a mi entender, ninguna intuición de la realidad en tanto que intelección directa, simple, inmediata, y por ventura completa y perfecta, del ser real. Habiendo rechazado todo "ontologismo" en otro lugar, no es menester volver sobre el asunto. Por otro lado, la experiencia sola _-incluyendo la experiencia ya organizada o experiencia letterata en el sentido de Bacon- no basta tampoco para fundamentar una ontología, como si ésta fuera simplemente una especie de recapitulación conceptual de la experiencia. Hay, pues, que admitir por lo menos dos factores, estrechamente relacionados entre sí. Uno es lo que E. W. Beth ha llamado "ciertas consideraciones intuitivas" en la formulación de todo cuerpo de doctrina ontológico. El otro es el hecho de que el sujeto cognoscente, con su organización neurofisiológica, está en el mundo en forma tal que le es posible objetivar las impresiones y las experiencias. Estos dos factores juntamente hacen posible una especie de "sentido de la realidad" sin el cual ninguna reflexión ontológica sería siquiera concebible. Este "sentido de la realidad" no es, por descontado, una intuición directa del ser real. Pero no es tampoco el resultado automático de las objetivaciones que hacen posible todo conocimiento. Es como una "disposición" que se constituye en vista de un modo de estar en el mundo y a la vez como resultado de este estar en el mundo. Por eso el sentido de la realidad aludido no es ni puramente innato ni tampoco puramente adquirido. Consiste en adquirirse o, mejor dicho, en co-adquirirse lentamente, por medio de un número indefinido, y siempre rectificable, o cuando menos falible, de impresiones, experiencias, reflexiones, hipótesis, confirmaciones, refutaciones, crítica de cuerpos de doctrina establecidos y hasta, si se quiere, especulaciones.

Pero volvamos a nuestro problema. Si del modelo lógico no se puede deducir, o inferir, qué entidades hay $-o$ cuáles son las que hay-, menos aún se puede deducir, o inferir de tal modelo en qué consiste haberlas, es decir, qué es el ser real. Sin abandonar el modelo lógico hay, pues, que emprender una reflexión que aspira a ser todo lo sistemática que pueda, pero que reconoce su carácter perennemente falible y, por decirlo así, "tentativo". El hecho de emprender tal reflexión indica, claro está, que me parece justificada, pero de esto a pretender que pueda siempre justificarse hay un abismo. La empresa ontológica es resultado de una convicción sui generis: una convicción que hurga constantemente en sí misma, como si no estuviera nunca del todo plenamente convencida. Para filosofar es menester, 
desde luego, "familiarizarse" con el universo de problemas que llamamos "filosóficos"; de lo contrario, la filosofía carecería de sentido. Pero la familiaridad con la filosof́a es también harto peculiar, porque comporta el reconocimiento de argumentos de mucho peso contra ella. Ahora mismo podría aducir razones poderosas para probar que si la ontología consiste, como de hecho consiste, en un análisis de conceptos, son penas de amor perdidas, porque ningún análisis de conceptos puede desembocar en la realidad. A algunas de estas razones se debe el que se haya propuesto limitar la "filosofía" a un modo verbal, o modo formal de hablar, destinado a hacer explícitos los usos normales de expresiones aparentemente cargadas de problemas, pero en verdad horras de ellos. De este modo se podría, al parecer, deshacer las ilusiones creadas por un uso "anormal" del lenguaje, que sería justamente el llamado "uso filosófico". Ahora bien, si los argumentos destinados a probar que las disputas filosóficas son vanas, resultan muy convincentes, los argumentos destinados a probar que las disputas filosóficas - $y$, cö ello, la filosofía misma - son inevitables, no lo son menos. No, sin embargo, porque el hombre sea un "animal metafísico" y no pueda hacer nada contra este pecado original, sino porque las meditaciones filosóficas, y las disputas subsecuentes, están fundadas en los problemas que plantea la realidad. La filosofía, y su culminación (o, según se mire, su base), la ontología, no es una enfermedad, ni siquiera una enfermedad crónica: es una visión de la realidad que, a diferencia de otras, tiene en cuenta el carácter fundamentalmente problemático de esta visión. Ningún argumento de peso contra la posibilidad misma de la filosofía puede dejar de ser filosófico: a la filosofía, y no a otra actividad, pertenece el ser desconfiado ante ella. Pero la desconfianza de la filosofía con respecto a sí misma es precisamente el motor de la reflexión filosófica. Es éste el motor que echa andar la maquinaria ontologica que nos hemos puesto a aparejar. ${ }^{1}$

José FERRATER Mora

Bryn Mawr College

Bryn Mawr, Penn.

U. S. A.

1 Estas páginas constituyen la primera versión de una serie de reflexiones que, convenientemente depuradas, sistematizadas, y en buena parte corregidas y modificadas, han entrado a formar parte del libro del autor, El ser y el sentido, actualmente en prensa (Ediciones de la Revista de Occidente, S. A., Madrid). Agradezco a Diánoia, y en particular al Director del Centro de Estudios Filosóficos de la Universidad Nacional Autónoma de México, Dr. Fernando Salmerón, la oportunidad de publicar estas páginas y de hacer así posible la comparación entre "los primeros" y "los últimos pasos" en una dilucidación ontologica. 